\title{
Adverse selection in the annuity market when payoffs vary over the time of retirement
}

\author{
by \\ JOHANN K. BRUnNER AND SuSANNE PECH * \\ July 2004 \\ Revised Version of Working Paper 0030, \\ Department of Economics, University of Linz.
}

\begin{abstract}
This study deals with a specific implication of adverse selection on annuity pricing. Varying the time-path of the payoffs over the retirement periods affects annuity demand and welfare of individuals with low and high life expectancy in different ways. Therefore they can be separated by insurance firms through appropriate contract offers. We show that in this framework a Nash-Cournot equilibrium may not exist; if one exists, it will be a separating equilibrium. On the other hand, even if a separating equilibrium does not exist, a Wilson pooling equilibrium exists. (JEL: D82, D91, G22)

* Address: Department of Economics, University of Linz, Altenberger Straße 69, A-4040 Linz, Austria. Phone: +43-732-2468-8248, -8593, FAX: -9821.E-mail: johann.brunner@jku.at, susanne.pech@jku.at.
\end{abstract}




\section{Introduction}

Private life-annuity markets are frequently recognized as being weak. That is, less lifeannuities are demanded than one could expect, given the need to insure against uncertainty about the duration of life, in order to smooth consumption appropriately over one's lifetime. Empirical evidence for this fact, which is sometimes called the "annuity puzzle", has been established in various studies for the US (see, e.g., MoORE AND MitChell [2000], FRIEDMAN AND WARShaWSKy [1990]), but also for the U.K., Canada and other countries (for an overview see BROwN [2001]).

To the extent that the low demand is explained by a bequest motive or by the existence of a public pension system, the weakness is not attributed to an intrinsic problem of this market. However, there is a further reason put forward in the literature, namely asymmetric information which leads to adverse selection: The fact that individuals have more information about their life expectancy than annuity companies leads to an overrepresentation of persons with a high survival probability among the buyers of annuity contracts, which in turn drives down the rate of return on annuities below the rate corresponding to the average probability of survival. ${ }^{1}$ As a consequence of this phenomenon, a loss of welfare arises for persons who cannot buy an appropriate annuity contract. This shortcoming of the annuity market is supposed to become increasingly important, because in many countries the existing public pension system, organized

\footnotetext{
${ }^{1}$ Empirical evidence suggests that none of these three reasons alone, but only the interaction of adverse selection, public pension system and bequest motives can explain the weakness of the market. See, e.g., FRIEDMAN AND WARSHAWSKY [1988, 1990], WALLISER [2000], MitCHELL ET AL. [1999].
} 
according to the pay-as-you-go method, is expected to allow only a reduced replacement-ratio in the future, hence increased private insurance will be required.

In the present paper we focus on the fact that annuity contracts provide periodic payouts for the duration of the annuitants' life (or at least for a fixed number of years). We point out a further consequence of the asymmetric information problem, in addition to the adverse-selection problem described so far: The time structure of the payoffs matters. Individuals with low life expectancy will put less weight on the payment they may not receive in the last period of life than individuals with high life expectancy do. This fact can be used by firms to offer annuity contracts which are favourable for low-risk individuals but not for high-risk individuals.

Indeed, in two recent empirical papers, FINKELSTEIN AND POTERBA [2002, 2004] have found evidence for such selection effects in the U.K. annuities market. They analyzed three types of annuity contracts, which differ in the time-path of payoffs: constant nominal payoffs, annually escalating nominal payoffs and inflation-indexed payoffs. They showed that for the latter two contracts the expected present value of the payoffs, based on the average population mortality, is significantly lower than that for fixed nominal annuities. This result suggests that those two contracts, which provide the higher payoffs in later years, are selected by individuals with a high life-expectancy: Only these individuals have an incentive to buy such contracts, because for them the expected present value of the payoffs, based on their low mortality rates, is higher and may exceed that of annuities with decreasing real (i.e. fixed nominal) payoffs; the latter 
are favourable for individuals with lower life-expectancy. ${ }^{2}$ In fact, estimating a hazard model regarding the annuitants' life-spans, FinKELSTEIN AND POTERBA [2004] found clear evidence for such an annuitant self-selection with respect to the time profile of payoffs. Moreover, the selection effects turned out to be quite large.

In the present contribution we provide a theoretical analysis of the functioning of annuity markets, when selection through the timing of payoffs takes place. In particular, we investigate the reaction of insurance demand and the consequences for the existence of equilibria, if insurers offer contracts which vary with respect to the time-path of the payoffs.

In the model usually employed for the analysis of annuity markets (see PAULY [1974], ABEL [1986] and WALLISER [2000]), there is one period of retirement, and there are two groups of individuals with differing life expectancy. Competition takes place via prices (i.e. via the rate of return, that is the pension payment per unit of annuity), which are fixed by the firms. Individuals can buy as many annuities as they want. As is wellknown, in this framework only a pooling equilibrium is possible, where all individuals receive the same rate of return.

We extend this model by introducing two periods of retirement, to which the individuals may or may not survive, and by assuming that the payoffs need not be the same in both

\footnotetext{
${ }^{2}$ The lower expected present discounted value of the real annuity, based on average mortality, may partly also arise, because a premium for the insurance against inflation has to be paid. The market for real annuities is analyzed in BROWN, Mitchell AND Poterba [2001], who study the role of governmentissued inflation indexed bonds and other securities as instruments, which insurance companies use to hedge price level risks (primarily in the UK and US). However, the authors do not consider selection effects.
} 
periods. This implies that contracts are characterized by two prices, set by the firms. The important aspect in this extended model is that - in accordance with the observation mentioned above - annuity demand as well as welfare of the individuals are sensitive with respect to the time structure of the payoffs, and the possibility arises for firms to separate buyers according to their survival probabilities. This additional separation effect, which was up to now neglected in the theoretical literature, may represent a further explanation for the fact that annuity markets are not well developed. Indeed, it turns out that in such a market no Nash-Cournot equilibrium may exist. If one exists, it will be a separating equilibrium.

The Nash-Cournot equilibrium in insurance markets was studied by ROTHSCHILD AND STIGLITZ [1976]. In their framework firms offer a number of different contracts which specify both a price and a quantity. Individuals who prefer a higher quantity are willing to pay a higher price for it. A prerequisite for the existence of price and quantity competition is that individuals can buy at most one contract, which may be a reasonable assumption for some insurance markets, e.g. insurance against accidents, but seems difficult to apply to the annuity market. ${ }^{3}$ Consequently, in our model individuals are free to buy as many annuities as they want. Separation becomes possible because firms can fix two prices instead of a price and a quantity.

As a potential answer to the question of what happens in an insurance market, if no Nash-Cournot-equilibrium exists, WILSON [1977] introduced a different equilibrium

3 ECKSTEIn, EICHENBAUM AND PELED [1985] make indeed the assumption of a price and quantity competition for the annuity market with one period of retirement only. In this framework they derive the same results as ROTHSCHILD AND STIGLITZ [1976]. 
concept, which is based on specific beliefs of firms concerning the reaction of other firms to new contract offers. We show that a Wilson equilibrium always exists in our model.

Other studies which quit the assumption of a single period of retirement are by TOWNLEy AND BoAdWAy [1988] and FeldSTEIn [1990]. Feldstein considers a public pension system, organized according to the pay-as-you-go method, and discusses the time structure of the benefits. He assumes two periods of retirement, but only survival to the second is uncertain. In this framework current population prefers to receive benefits either in the first or in the second period of retirement, depending on whether the return on social security is lower or higher than the expected return on private saving. However, steady-state welfare is maximized by paying benefits only in the first retirement period, since this increases savings and therefore unintended bequests.

The paper by TOWNLEY AND BOADWAY [1988] deals with the market for private annuities and is, thus, more related to the present contribution. The authors model the life-span from retirement to death in continuous time and consider term-insured annuity contracts, i.e. contracts which guarantee a stream of payoffs for a limited time, either until the insured individual dies or until the term of the annuity expires. In their analysis of equilibria, Townley and Boadway take the stream of payoffs as constant over the whole duration; hence the contracts are characterized by two parameters: the term (duration) and the payoff (per unit of money invested). In contrast to our model, where firms can separate costumers through a variation of the payment over time, Townley and Boadway study separation effects with respect to the term of the annuity: 
Individuals with longer expected life-span estimate a contract with a longer duration higher than individuals with shorter expected life-span. In the framework of their model, with asymmetric information concerning life-expectancy, no equilibrium may exist, if it exists, it is either a pooling equilibrium or a separating equilibrium.

In TOWNLEY AND BOADWAY [1988] individuals can make provision for the time after expiry of the annuity through private savings only. In a related study (BRUNNER AND PECH [2002]), we have considered a model which also takes the existence of timelimited annuity contracts into account, but allows individuals to provide for the time after expiry of the annuity by purchasing another annuity. That is, individuals need not make their decision concerning old-age provision for the whole time of retirement at once, but can do so sequentially. In this framework it turns out that only a situation, where all individuals decide sequentially, represents an equilibrium, which is to the disadvantage of the short-living individuals.

The rest of our paper proceeds as follows: In Section 2 we introduce the basic model of consumption behaviour under asymmetric information with two periods of retirement, where individuals provide for old-age by buying annuities. We analyze the effect of a variation in the time structure of the payoffs on annuity demand and on welfare of an individual under uncertain lifetime. In Section 3 we turn to the investigation of equilibria. First, we derive all results concerning the existence and characterization of the equilibria in the basic model. Then we extend the model and allow individuals to save in riskless bonds in addition to annuities. Section 4 contains concluding remarks. 


\section{Annuity demand in a model with two periods of retirement}

\subsection{The basic model with asymmetric information}

Consider an economy with $\mathrm{N}$ individuals who live for a maximum of three periods $t=0,1,2$. In the working period $t=0$ individual $i$ earns a fixed labour income $w$, spends an amount $A^{i}$ on annuities and consumes an amount $c_{O}^{i}$. This gives the budget equation for period 0:

$$
c_{0}^{i}=w-A^{i} .
$$

The individuals retire at the end of period 0. Through the purchase of annuities they make provision for future consumption in the two periods of retirement $t=1,2$. An annuity contract is characterized by the payoffs $\left(q_{1}, q_{2}\right)$ : An annuity $A^{i}=1$ pays $q_{t}$ units of money to the individual in the retirement periods $t=1,2$, if she survives. Hence, for individual $i$ the budget equations for the two retirement periods are

$$
\begin{aligned}
& c_{1}^{i}=q_{1} A^{i}, \\
& c_{2}^{i}=q_{2} A^{i} .
\end{aligned}
$$

The budget equations (1) - (3) are built on the assumption that the individuals do not save and buy other assets, in addition to annuities. At this stage of the analysis we exclude holding other assets, in order to concentrate on the design of the annuity 
contracts. However, the possibility of buying bonds in the working period and in the first period of retirement is explicitly considered in Section 3.4, and it will be shown that this does not change the main results derived in the basic model. Further, for the sake of simplicity, the assumption is made that no public pension system exists. ${ }^{4}$

Survival to period $t=1$ is uncertain and occurs with probability $\pi_{1}^{i}, 0<\pi_{1}^{i}<1$. In the same way, given that an individual is alive in period 1, survival to period 2 occurs with probability $\pi_{2}^{i}, 0<\pi_{2}^{i}<1$. Each individual decides on her consumption plan over the uncertain duration of her retirement by maximizing expected utility from a timeseparable utility function $U^{i}$,

(4) $U^{i}=\left(1-\pi_{1}^{i}\right) u\left(c_{0}^{i}\right)+\pi_{1}^{i}\left(1-\pi_{2}^{i}\right)\left(u\left(c_{0}^{i}\right)+\alpha u\left(c_{1}^{i}\right)\right)+\pi_{1}^{i} \pi_{2}^{i}\left(u\left(c_{0}^{i}\right)+\alpha u\left(c_{1}^{i}\right)+\alpha^{2} u\left(c_{2}^{i}\right)\right)$,

subject to conditions (1), (2) and (3). In (4) $u\left(c_{t}^{i}\right)$ describes utility of consumption per period, where we assume that $u^{\prime}\left(c_{t}^{i}\right)>0, u^{\prime \prime}\left(c_{t}^{i}\right)<0$ and $\lim _{c \rightarrow 0} u^{\prime}(c)=\infty$. $\alpha$ denotes the one-period discount factor of utility, with $0<\alpha \leq 1$. Notice that the specification in (4) means that the individuals discount future consumption for two reasons, risk aversion and time preference. (4) can be reduced to

$$
U^{i}=u\left(c_{0}^{i}\right)+\pi_{1}^{i} \alpha u\left(c_{1}^{i}\right)+\pi_{1}^{i} \pi_{2}^{i} \alpha^{2} u\left(c_{2}^{i}\right)
$$

4 In Section 4 we discuss the consequences for our results, if a public pension system is introduced in the model. 
Inserting (1), (2) and (3) into (4') and differentiating with respect to $A^{i}$ yields the first order condition of this maximization problem as

$$
-u^{\prime}\left(c_{0}^{i}\right)+\pi_{1}^{i} \alpha q_{1} u^{\prime}\left(c_{1}^{i}\right)+\pi_{1}^{i} \pi_{2}^{i} \alpha^{2} q_{2} u^{\prime}\left(c_{2}^{i}\right)=0 .
$$

From (2) and (3) we know that $c_{1}^{i} \gtreqless c_{2}^{i}$ corresponds to $q_{1} \gtreqless q_{2}$. Let $A^{i}\left(q_{1}, q_{2}\right)$ be the annuity demand determined by (5), for given $\left(q_{1}, q_{2}\right)$.

From now on we assume that the otherwise identical individuals are divided into two groups $i=L, H$, characterized by different risks of a long life, i.e. by different probabilities of survival $\pi_{t}^{H}>\pi_{t}^{L}$ for $t=1$,2. Let $\gamma$ and $(1-\gamma)$ denote the share of the high-risk and low-risk individuals, resp., with $0<\gamma<1$. The probabilities $\pi_{t}^{i}$ and the share $\gamma$ are public information, known by the annuity companies. But it is the private information for each individual to know her type, i.e. her probability of survival. As a consequence, there is an adverse-selection problem in the annuity market. This is illustrated by the following lemma, which shows that high-risk individuals buy more annuities than low-risk individuals, given any contract $\left(q_{1}, q_{2}\right)$.

Lemma 1: For any contract $\left(q_{1}, q_{2}\right)$ an individual with high survival probabilities will demand a larger quantity of annuities than an individual with low survival probabilities, i.e. $A^{H}\left(q_{1}, q_{2}\right)>A^{L}\left(q_{1}, q_{2}\right){ }^{5}$

\footnotetext{
${ }^{5}$ The proofs of all Lemmas and Propositions are relegated to the Appendix A.1.
} 
This result implies that if there is only a single contract offered in the annuity market, with some given payoffs $\left(q_{1}, q_{2}\right)$ per period, then the share of annuity purchases of highrisk individuals in total annuity demand is larger than $\gamma$, which is the share of high-risk individuals in the economy.

\subsection{Separating and pooling contracts}

An annuity contract $\left(q_{1}^{i}, q_{2}^{i}\right)$ is said to be individually fair for an individual of type $i=L, H$, if expected payoffs equal the price, i.e. if it fulfills

$$
1-\pi_{1}^{i} q_{1}^{i}-\pi_{1}^{i} \pi_{2}^{i} q_{2}^{i}=0
$$

given the assumption of a zero interest rate, which is chosen for the sake of simplicity; a positive interest rate would not affect the qualitative results. Obviously, (6) implies that the annuity companies make zero expected profits, given that solely individuals of type $i$ buy their individually fair contracts. However, as there exist many contracts $\left(q_{1}^{i}, q_{2}^{i}\right)$ which fulfill (6), it is interesting to investigate which of the individually fair annuity contracts is the most preferred one by an individual of type $i$. The next Lemma provides a characterization.

Lemma 2: Among all individually fair contracts $\left(q_{1}^{i}, q_{2}^{i}\right)$ for an individual of type $i$, the most preferred is characterized by 


$$
u^{\prime}\left(c_{1}^{i}\right)=\alpha u^{\prime}\left(c_{2}^{i}\right)
$$

which implies that $q_{1}^{i}>q_{2}^{i}$, if $\alpha<1$ and $q_{1}^{i}=q_{2}^{i}$, if $\alpha=1$.

That is, in case of a zero rate of time preference $(\alpha=1)$, an equal distribution of the payoffs $\left(q_{1}^{i} / q_{2}^{i}=1\right)$ over the two periods of retirement is optimal, for both types $i=L, H$, given their respective individually fair contract. For $\alpha<1$, however, the optimum ratio $q_{1}^{i} / q_{2}^{i}(>1)$, determined by (7), will in general be different for the two types, because in this case the optimum ratio depends on the respective annuity demand $A^{L}$ and $A^{H}$, which will be different. (But one checks easily that the most preferred ratio $q_{1}^{i} / q_{2}^{i}$ is independent of $A^{i}$ and thus identical for both types, in case of a per-period utility function $u$ which exhibits a constant relative risk aversion, irrespective of the rate of time preference.)

Note, moreover, that with the most preferred individually fair contract the relation (7), which characterizes the optimum division of consumption between the two periods of retirement, also applies for the allocation decision between consumption in the working period and the first period of retirement, namely

$$
u^{\prime}\left(c_{0}^{i}\right)=\alpha u^{\prime}\left(c_{1}^{i}\right)
$$

This can be seen when eliminating $u^{\prime}\left(c_{2}^{i}\right)$ in (5) by use of (7), which yields $u^{\prime}\left(c_{0}^{i}\right)=\alpha u^{\prime}\left(c_{1}^{i}\right)\left(\pi_{1}^{i} q_{1}^{i}+\pi_{1}^{i} \pi_{2}^{i} q_{2}^{i}\right)$. Substituting (6) into this condition, it reduces to (8). It 
follows that an individual, who does not discount future consumption due to time preference $(\alpha=1)$, consumes the same amount in all three periods of life, i.e. $c_{0}^{i}=c_{1}^{i}=c_{2}^{i}$. Otherwise $(\alpha<1)$, she chooses $c_{0}^{i}>c_{1}^{i}>c_{2}^{i}$.

The assumption $\pi_{t}^{L}<\pi_{t}^{H}, t=1$,2, implies that individual fairness (condition (6)) for each group can be fulfilled only with two separate contracts. If each is bought by the respective risk group, both produce zero profits. On the other hand, a contract $\left(q_{1}, q_{2}\right)$ which is bought by both groups, is called a pooling contract. In order that a pooling contract produces zero profits, it must fulfill the condition (for shortness we use $A^{i}$ instead of $\left.A^{i}\left(q_{1}, q_{2}\right)\right)$

$$
(1-\gamma) A^{L}\left(1-q_{1} \pi_{1}^{L}-q_{2} \pi_{1}^{L} \pi_{2}^{L}\right)+\gamma A^{H}\left(1-q_{1} \pi_{1}^{H}-q_{2} \pi_{1}^{H} \pi_{2}^{H}\right)=0 .
$$

Zero-profit contracts (whether separate or pooling) are of special interest, because under the assumption of perfect competition in the annuity market, only such contracts can persist. (9) can also be written as

$$
1+\rho\left(q_{1}, q_{2}\right)-q_{1}\left(\pi_{1}^{L}+\rho\left(q_{1}, q_{2}\right) \pi_{1}^{H}\right)-q_{2}\left(\pi_{1}^{L} \pi_{2}^{L}+\rho\left(q_{1}, q_{2}\right) \pi_{1}^{H} \pi_{2}^{H}\right)=0
$$

where $\rho$ is defined by $\rho\left(q_{1}, q_{2}\right) \equiv\left(\gamma A^{H}\left(q_{1}, q_{2}\right)\right) /\left((1-\gamma) A^{L}\left(q_{1}, q_{2}\right)\right)$, that is the ratio of annuity demand of both groups. Note that $\rho$ depends on $\left(q_{1}, q_{2}\right)$, but for shortness, we usually do not indicate this dependency. Of course, our assumptions on the survival probabilities imply that for the low-risk individuals expected returns from a zero-profit 
pooling contract are lower than required for individual fairness $\left(1-q_{1} \pi_{1}^{L}-q_{2} \pi_{1}^{L} \pi_{2}^{L}>0\right)$, while for the high-risk individuals they are higher $\left(1-q_{1} \pi_{1}^{H}-q_{2} \pi_{1}^{H} \pi_{2}^{H}<0\right)$.

\subsection{Varying the payoff-ratio of a pooling contract}

In the Lemmas 3 and 4 below, we consider a zero-profit pooling contract and investigate the effect of a marginal change in the payoffs on indirect utility and on annuity demand of an individual of type $i=L, H$. Clearly, if $q_{1}\left(\right.$ or $\left.q_{2}\right)$ is increased alone, then both groups benefit and buy more annuities. However, such an increase would produce a loss for the annuity companies. Hence, the interesting case is when $q_{1}$ is increased at the expense of $q_{2}$ (or vice versa), such that the zero-profit condition (9) remains fulfilled. We characterize the first-round effect on indirect utility and on annuity demand of a marginal increase of $q_{1}$, when the associated change of $q_{2}$, such that (9') remains fulfilled, is calculated under the assumption of a constant ratio $\rho$ of annuity demand of the two groups. Moreover we discuss the conditions necessary for the second-round effects (i.e. the influence of the payoffs on $\rho$ ) not to outweigh the first-round effects.

In Lemma 3(i) we consider a contract with a ratio of the payoffs, which is optimal for an individual of type $L$ according to condition (7) for an individually fair contract. We show that this ratio is no longer optimal in case of a zero-profit pooling contract: The low-risk individual benefits, if $q_{1}$ is increased. An analogous result is found for a highrisk individual (Lemma 3(ii)): She benefits if $q_{1}$ is reduced. 
Lemma 3: Consider two pooling contracts $\left(q_{1}^{\prime}, q_{2}^{\prime}\right),\left(q_{1}^{\prime \prime}, q_{2}^{\prime \prime}\right)$ where each, together with annuity demand of the two groups, fulfills the zero-profit condition (9').

(i) If the payoff ratio $q_{1}^{\prime} / q_{2}^{\prime}$ satisfies the condition (7) for an optimal individually fair contract for type $L$, a marginal increase of $q_{1}$ (and thus a marginal decrease of $q_{2}$ ) where (9') for fixed $\rho$ remains fulfilled, makes an individual of type $L$ better off.

(ii) If the payoff ratio $q_{1}^{\prime \prime} / q_{2}^{\prime \prime}$ satisfies the condition (7) for an optimal individually fair contract for type $H$, a marginal increase of $q_{1}$ (and thus a marginal decrease of $q_{2}$ ) where (9') for fixed $\rho$ remains fulfilled, makes an individual of type $H$ worse off.

This first-round effect described in Lemma 3 is of particular interest, because it reveals the mechanism which is responsible for the negative result concerning the existence of a pooling contract in equilibrium (see Section 3.1). For an illustration, consider the case $\alpha=1$, which means - as we know from Lemma 2 - that both individuals prefer an equal distribution of the payoffs over the two periods of retirement, given their respective individually fair contract. However, in case of a zero-profit pooling contract, such an equal distribution of the payoffs is no longer optimal: Individuals with low lifeexpectancy are better off, if $q_{1}$, the payoff in the first period of retirement, is increased at the expense of $q_{2}$, while the opposite holds for individuals with high life-expectancy. Thus, the annuity companies have an incentive to design separate contracts for the two groups.

The intuitive reason why a low-risk individual finds a shift of consumption from period 2 to period 1 attractive can easily be explained for $\alpha=1$ (and thus starting from $q_{1}=q_{2}$ ) 
as follows: If $q_{1}$ is increased by one, $q_{2}$ is decreased by $\left|d q_{2} / d q_{1}\right|$, which is determined by the requirement that the zero-profit condition (9') be preserved. Since with a pooling contract the associated decrease of $q_{2}$ goes more to the expense of the high-risk individuals, it turns out from (9') that $\left|d q_{2} / d q_{1}\right|<1 / \pi_{2}^{L}$ (for constant $\rho$ ). As a result, for type- $L$ individuals the expected loss in period $2, \pi_{2}^{L}\left|d q_{2} / d q_{1}\right|$, is lower than one and they benefit from a shift towards increasing $q_{1}$. (Note that due to $q_{1}=q_{2}$, marginal utility is equal in both periods.) By the same reasoning and observing that, on the other hand, $\left|d q_{2} / d q_{1}\right|>1 / \pi_{2}^{H}$ holds, type- $H$ individuals, who expect to live longer, are better off by a shift towards reducing $q_{1}$. Similar considerations apply for the case of $\alpha<1$.

Obviously also the second-round effect, that is the effect $\partial \rho / \partial q_{t}$ of the change of the payoffs on (the ratio of) annuity demand of the two groups, matters, as can be seen from (A6) in the Appendix. The above consideration certainly maintains, if both $\partial \rho / \partial q_{t}$, $t=1,2$, are sufficiently small, otherwise an appropriate relation between them must hold. (For instance, a sufficient, but not necessary condition is $\pi_{2}^{H} \partial \rho / \partial q_{1} \geq \partial \rho / \partial q_{2} \geq \pi_{2}^{L} \partial \rho / \partial q_{1}$, which ensures that the second-round effect goes into the same direction as the first-round effect.)

Remark: Inspection of the proof of the foregoing Lemma shows that an increase of $q_{1}$ at the expense of $q_{2}$ improves welfare of low-risk individuals also if initially the ratio $q_{1} / q_{2}$ is lower than that determined by the optimality condition (7) for individually fair contracts. It follows that their most preferred pooling contract exhibits a higher ratio (that is, in case of $\alpha=1$ : $q_{1}>q_{2}$ ). By similar reasoning one finds for the high-risk 
individuals that their most preferred pooling contract exhibits a lower payoff-ratio than that determined by (7) (which means $q_{1}<q_{2}$ in case of $\alpha=1$ ).

A characterization of the effect of a marginal change of $q_{1}$ (and $q_{2}$ ) on annuity demand is given in the following Lemma, again starting from a zero-profit pooling contract with a payoff-ratio which satisfies (7) for the respective optimal individually fair contract. We restrict attention to the case where the discount factor $\alpha$ equals one or the per-period utility function exhibits a constant coefficient of relative risk aversion in the sense of Arrow-Pratt, defined as $R \equiv-c_{t}^{i} u^{\prime \prime}\left(c_{t}^{i}\right) / u^{\prime}\left(c_{t}^{i}\right)$. Then, as mentioned above, the optimal payoff-ratio, given an individually fair contract, is the same for both risk-types (and equal to 1 , if $\alpha=1$ ).

Lemma 4: Assume that $\alpha=1$ or that $R$ is constant. Consider a pooling contract $\left(q_{1}^{\prime}, q_{2}^{\prime}\right)$ which, together with annuity demand of the two groups, fulfills the zero-profit condition $\left(9^{\prime}\right)$ and whose payoff ratio $q_{1}^{\prime} / q_{2}^{\prime}$ is determined by the condition (7) for an optimal individually fair contract for both types $i=L, H$. Then the effect of a marginal increase of $q_{1}$ on the annuity demand of each individual $i=L, H$, where (9') for fixed $\rho$ remains fulfilled, depends on the relative risk aversion in the following way:

$$
\text { Iff } R \lesseqgtr 1 \text {, then } \frac{d A^{H}}{d q_{1}} \lesseqgtr 0 \text { and } \frac{d A^{L}}{d q_{1}} \gtreqless 0 \text {. }
$$

This result follows from the fact that, per definition, the effect of an increase of $q_{1}$ on $q_{1} u^{\prime}\left(q_{1} A^{i}\right)$, i.e. on the marginal utility of $A^{i}$ in period 1 , can be written as $(1-R)$, and the 
same applies to period 2. Hence, whether an increase of $q_{1}$ at the expense of $q_{2}$ increases or decreases expected marginal utility of $A^{i}$ (in both retirement periods together) depends on $\left(1+\pi_{2}^{i} d q_{2} / d q_{1}\right)(1-R)$, where, as argued above, $\pi_{2}^{i} d q_{2} / d q_{1}$ describes the expected loss in period 2, if $\mathrm{q}_{1}$ is increased and the zero-profit condition is preserved. (Note that, by assumption, either $q_{1}=q_{2}$ which means that $\mathrm{R}$ is equal in both periods, or $\mathrm{R}$ is constant at all.) We know from above that $1+\pi_{2}^{i} d q_{2} / d q_{1}$ is positive for $i=L$ and negative for $i=H$, given a fixed ratio $\rho$ of annuity demand of both groups. Thus we find that, in case of $\mathrm{R}<1$, for type- $L$ individuals the expected marginal utility of $A^{L}$ in the two periods of retirement increases, if $q_{1}$ is increased at the expense of $q_{2}$. On the other hand, the decision on annuity demand is made by balancing the (negative) marginal utility of $A^{L}$ in the working period against the expected (positive) marginal utility in retirement. It is intuitively clear that demand increases, if the latter increases (the former is unaffected by a change of $q_{1}$ and $q_{2}$ ). Moreover, in case of $R>1$, the effect obviously goes towards a decrease of $A^{L}$, and similar consideration hold for type- $H$ individuals.

\section{Equilibria}

Introducing two instead of one retirement period in the model allows annuity companies to offer contracts which differ in the division of the payoffs over time. In this section it is shown that this implies the possibility of a separating equilibrium, which means that annuity companies separate individuals according to their survival probabilities. To obtain this result we make use of the well-known concept of a Nash-Cournot equilibrium, which was studied by RoTHSCHILD AND STIGLITZ [1976] in the context of insurance markets. Our result is in contrast to studies considering one period of 
retirement only, which find that under price competition there will be a pooling equilibrium. In Subsection 3.3 we extend the analysis by introducing the concept of the WILSON [1977] equilibrium, where it is assumed that firms anticipate reactions of the other firms to new contract offers, viz. that they will withdraw unprofitable existing contracts. First we derive all results concerning the existence and characterization of equilibria in the model considered in Section 2, where individuals provide for retirement by buying annuities only, then we introduce, in Section 3.4, the possibility of saving in riskless bonds.

\subsection{The non-existence of a pooling equilibrium}

We call a contract $\left(q_{1}, q_{2}\right)$ a pooling equilibrium, if together with $A^{i}\left(q_{1}, q_{2}\right), i=L, H$, the zero-profit condition (9) is fulfilled and if no other contract exists, which is preferred to $\left(q_{1}, q_{2}\right)$ by at least one group $i \in\{L, H\}$ and which allows a nonnegative profit. Our main result is that in general no pooling equilibrium exists. As a preparation we show:

Lemma 5: Let $\left(q_{1}, q_{2}\right)$ be a pooling contract which together with $A^{i}\left(q_{1}, q_{2}\right), i=L, H$, fulfills the zero-profit condition (9). Any contract $\left(q_{1}+\delta q_{1}, q_{2}+\delta q_{2}\right)$, which is close enough to $\left(q_{1}, q_{2}\right)$ and which is chosen only by group $L$ (i.e. $A^{H}=0$ ) allows a nonnegative profit.

This result follows from the observation in Section 2.2 that a zero-profit pooling contract offers less expected returns to low-risk individuals than required for individual 
fairness. This in turn implies positive profits, if only the low-risk individuals buy this contract or one close to it.

We now introduce a further assumption on $U^{i}$, in addition to strict concavity of the instantaneous utility function $u$. Let indirect utility $U^{i}\left(q_{1}, q_{2}\right)$ for any contract $\left(q_{1}, q_{2}\right)$ be defined in the usual way as utility attained with annuity demand $A^{i}\left(q_{1}, q_{2}\right)$. We assume that indifference curves in the $\left(q_{1}, q_{2}\right)$-space satisfy the single-crossing condition

$$
-\frac{\partial U^{L} / \partial q_{1}}{\partial U^{L} / \partial q_{2}}<-\frac{\partial U^{H} / \partial q_{1}}{\partial U^{H} / \partial q_{2}} \text { for all }\left(q_{1}, q_{2}\right) \text {. }
$$

This condition, which is familiar from other models with asymmetric information, requires that the slope of an indifference curve of a low-risk individual is always steeper than that of a high-risk individual. Hence, indifference curves of the two groups can cross only once. Using the Envelope Theorem, (10) reduces to $u^{\prime}\left(q_{1} A^{L}\right) /\left(\alpha \pi_{2}^{L} u^{\prime}\left(q_{2} A^{L}\right)\right)>u^{\prime}\left(q_{1} A^{H}\right) /\left(\alpha \pi_{2}^{H} u^{\prime}\left(q_{2} A^{H}\right)\right)$, and one observes that, as $\pi_{2}^{L}<\pi_{2}^{H}$, the condition is certainly fulfilled for any utility function which exhibits a constant coefficient of relative risk aversion, hence, in particular, for logarithmic utility. Singlecrossing is needed for a concise formulation of the following Proposition 1 only; in the remark afterwards it will be argued that in general the Proposition holds without this assumption.

Proposition 1: No pooling equilibrium exists, given the single-crossing condition (10). 
This result can be illustrated in a diagram where the payoffs $q_{1}$ and $q_{2}$ are drawn on the axis (see Figure 1). The dashed line $Z P$ denotes the zero-profit condition (9) for a pooling contract, with slope $d q_{2} / d q_{1}$, as determined by (A6) in the Appendix. Consider any contract $\left(q_{1}, q_{2}\right)$ fulfilling (9), i.e. any point on $Z P$. Due to the single-crossing condition the slope of the indifference curve $U^{L}$ corresponding to the low-risk group is steeper than that of $U^{H}$, the indifference curve of the high-risk group. Therefore one can find a contract $\left(q_{1}+\delta q_{1}, q_{2}+\delta q_{2}\right)$, close to $\left(q_{1}, q_{2}\right)$, which is preferred by the low-risk individuals only - and is, therefore, profitable for the annuity companies, as Lemma 5 tells us. Hence $\left(q_{1}, q_{2}\right)$ does not represent a pooling equilibrium.

\section{Figure 1}

The non-existence of a pooling equilibrium

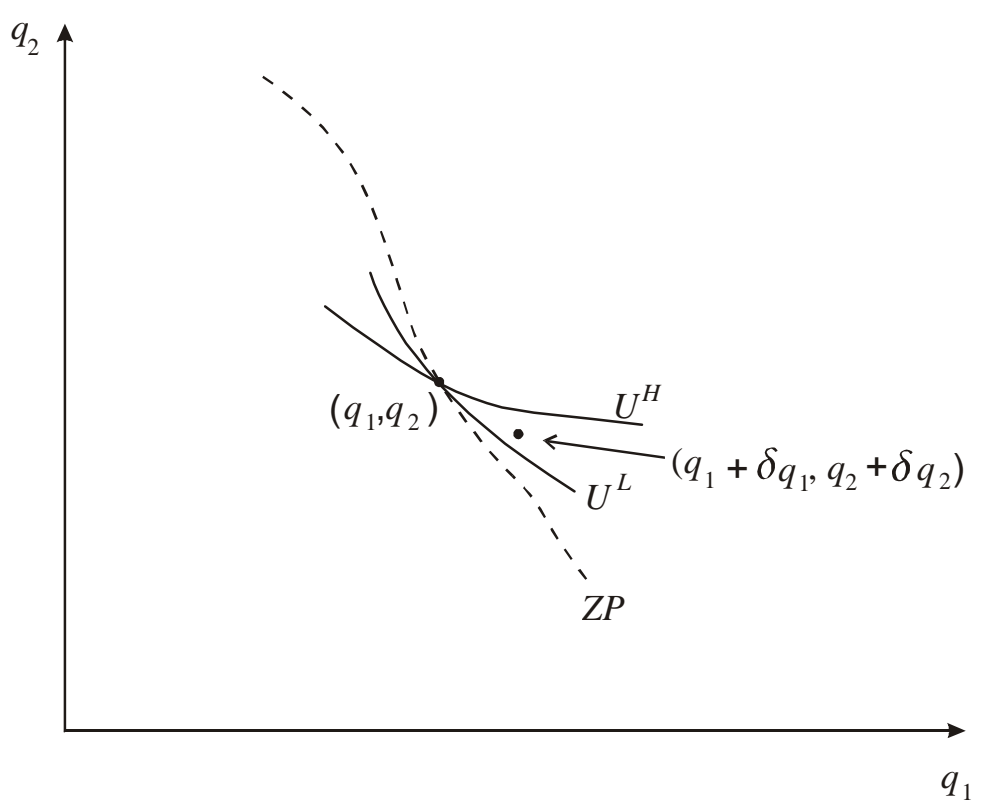

Remark: By means of Figure 1 the significance of the single-crossing condition can be discussed. One observes immediately that the result of Proposition 1 certainly holds as 
long as the slopes of $U^{L}$ and $U^{H}$ differ in $\left(q_{1}, q_{2}\right)$-space, independently of which one is steeper. Even if $U^{L}$ and $U^{H}$ have the same slope, the result holds, given that the slope of $\mathrm{ZP}$ is different. In this case one can find another pooling contract $\left(q_{1}+\delta q_{1}, q_{2}+\delta q_{2}\right)$ close to $\left(q_{1}, q_{2}\right)$ which is preferred by both groups and produces non-negative profits. Only if there exists a point on $Z P$ in which the slopes of $Z P, U^{L}$ and $U^{H}$ are identical, this represents a pooling equilibrium. Clearly, this case can occur for very specific parameter constellations only, a small perturbation of $\gamma$ or of $\pi_{t}^{i}$ would destroy the equilibrium. From these considerations we can conclude that in general Proposition 1 holds without assuming the single-crossing condition.

\subsection{The possibility of a separating equilibrium}

We call a set of two contracts $\left(q_{1}^{L}, q_{2}^{L}\right),\left(q_{1}^{H}, q_{2}^{H}\right)$ a separating equilibrium, if each fulfills the respective zero-profit condition (6), if group $L$ does not prefer $\left(q_{1}^{H}, q_{2}^{H}\right)$ to $\left(q_{1}^{L}, q_{2}^{L}\right)$ and vice versa, i.e. if

$$
\begin{aligned}
& U^{H}\left(q_{1}^{H}, q_{2}^{H}\right) \geq U^{H}\left(q_{1}^{L}, q_{2}^{L}\right), \\
& U^{L}\left(q_{1}^{L}, q_{2}^{L}\right) \geq U^{L}\left(q_{1}^{H}, q_{2}^{H}\right),
\end{aligned}
$$

and if no other contract exists, which is preferred to $\left(q_{1}^{i}, q_{2}^{i}\right)$ by at least one group $i \in\{L, H\}$ and which allows a nonnegative profit. 
As it is usual in this type of asymmetric-information models, we assume that if an individual is indifferent between the two contracts $\left(q_{1}^{L}, q_{2}^{L}\right)$ and $\left(q_{1}^{H}, q_{2}^{H}\right)$, she chooses indeed the particular contract which is designed for her. Moreover, each individual is restricted to buy only one type of contract, i.e. no mix of $\left(q_{1}^{L}, q_{2}^{L}\right)$ and $\left(q_{1}^{H}, q_{2}^{H}\right){ }^{6}$ However, individuals may purchase as many annuity contracts of the chosen type as they want.

We show that with these assumptions a separating equilibrium may, but need not exist, by referring to the logarithmic utility function. For simplicity we assume that the discount factor $\alpha$ equals one, then lifetime utility (4') for an individual $i=L, H$ reads

$$
U^{i}=\ln \left(c_{0}^{i}\right)+\pi_{1}^{i} \ln \left(c_{1}^{i}\right)+\pi_{1}^{i} \pi_{2}^{i} \ln \left(c_{2}^{i}\right) .
$$

(13) has two convenient properties: (i) As mentioned above, the single-crossing condition (10) is fulfilled, since at any $\left(q_{1}, q_{2}\right)$ the slope of the indifference curve, which is $-q_{2} /\left(\pi_{2}^{i} q_{1}\right)$, is flatter for a type- $H$ individual than for a type- $L$ individual. (ii) Annuity demand of any individual $i=L, H$ does not depend on the payoffs, since the coefficient of relative risk aversion $R$ is equal to one (see Lemma 4 and (A24) in Appendix A.3). These properties help to keep the analytical and graphical analysis simple.

6 This assumption is also implicit in TOWNLEY AND BOADWAY's [1988] analysis of the annuity market, and it is similar in spirit but, in the context of life annuities, less demanding than that applied by RothSCHILD AND STIGLITZ [1976] and by ECKSTEIN, EICHENBAUM AND PELED [1985]. They model price and quantity competition, which requires that individuals are restricted to buy only one insurance contract (otherwise all individuals would buy the contract where the price per unit of insurance is lowest). In reality, excluding individuals from buying a mix of contract types requires a system of information exchange among insurance companies. 
Let the two contracts $\left(\hat{q}_{1}^{H}, \hat{q}_{2}^{H}\right)$ and $\left(\bar{q}_{1}^{L}, \bar{q}_{2}^{L}\right)$ be defined as follows:

(i) $\left(\hat{q}_{1}^{H}, \hat{q}_{2}^{H}\right)$ is the most preferred individually fair contract for group $H$, therefore $\hat{q}_{1}^{H}=\hat{q}_{2}^{H}$ by Lemma 2, as $\alpha=1$ is assumed.

(ii) $\left(\bar{q}_{1}^{L}, \bar{q}_{2}^{L}\right)$ is implicitly defined by the zero-profit condition (6) for group $L$, by the property that high-risk individuals are indifferent between $\left(\hat{q}_{1}^{H}, \hat{q}_{2}^{H}\right)$ and $\left(\bar{q}_{1}^{L}, \bar{q}_{2}^{L}\right)$ and by $\bar{q}_{1}^{L}>\bar{q}_{2}^{L}$.

The way how $\left(\hat{q}_{1}^{H}, \hat{q}_{2}^{H}\right)$ and $\left(\bar{q}_{1}^{L}, \bar{q}_{2}^{L}\right)$ are defined is illustrated in Figure 2 . The straight lines $Z P^{i}, i=H, L$, represent the zero-profit conditions for group $i=L, H$ with respective slope $-1 / \pi_{2}^{i}$. Note for (ii) that with logarithmic utility the indifference curves in $\left(q_{1}, q_{2}\right)$ space are strictly convex with slope $-q_{2} /\left(\pi_{2}^{i} q_{1}\right)$, as mentioned above. Therefore the indifference curve $\hat{U}^{H}$ going through $\left(\hat{q}_{1}^{H}, \hat{q}_{2}^{H}\right)$ has exactly two points of intersections with the zero-profit condition $Z P^{L}$ for group $L . \bar{q}_{1}^{L}>\bar{q}_{2}^{L}$ uniquely defines the one below the $45^{\circ}$-line.

Obviously, the definition of $\left(\hat{q}_{1}^{H}, \hat{q}_{2}^{H}\right)$ and $\left(\bar{q}_{1}^{L}, \bar{q}_{2}^{L}\right)$ implies that each produces zeroprofits, if chosen only by the respective risk-group $i=L, H$, and this is ensured for group $H$ by the condition $U^{H}\left(\hat{q}_{1}^{H}, \hat{q}_{2}^{H}\right)=U^{H}\left(\bar{q}_{1}^{L}, \bar{q}_{2}^{L}\right)$, which means that the self-selection constraint (11) for this risk-group is fulfilled with equality. Moreover, it turns out that the self-selection (12) constraint for group $L$ holds as well: It is evident from Figure 2 
that low-risk individuals are better off with their separate contract $\left(\bar{q}_{1}^{L}, \bar{q}_{2}^{L}\right)$ than with $\left(\hat{q}_{1}^{H}, \hat{q}_{2}^{H}\right)$. This gives us an intuition for the next Lemma.

Figure 2

The possibility of a separating equilibrium $\left(\hat{q}_{1}^{H}, \hat{q}_{2}^{H}\right),\left(\bar{q}_{1}^{L}, \bar{q}_{2}^{L}\right)$

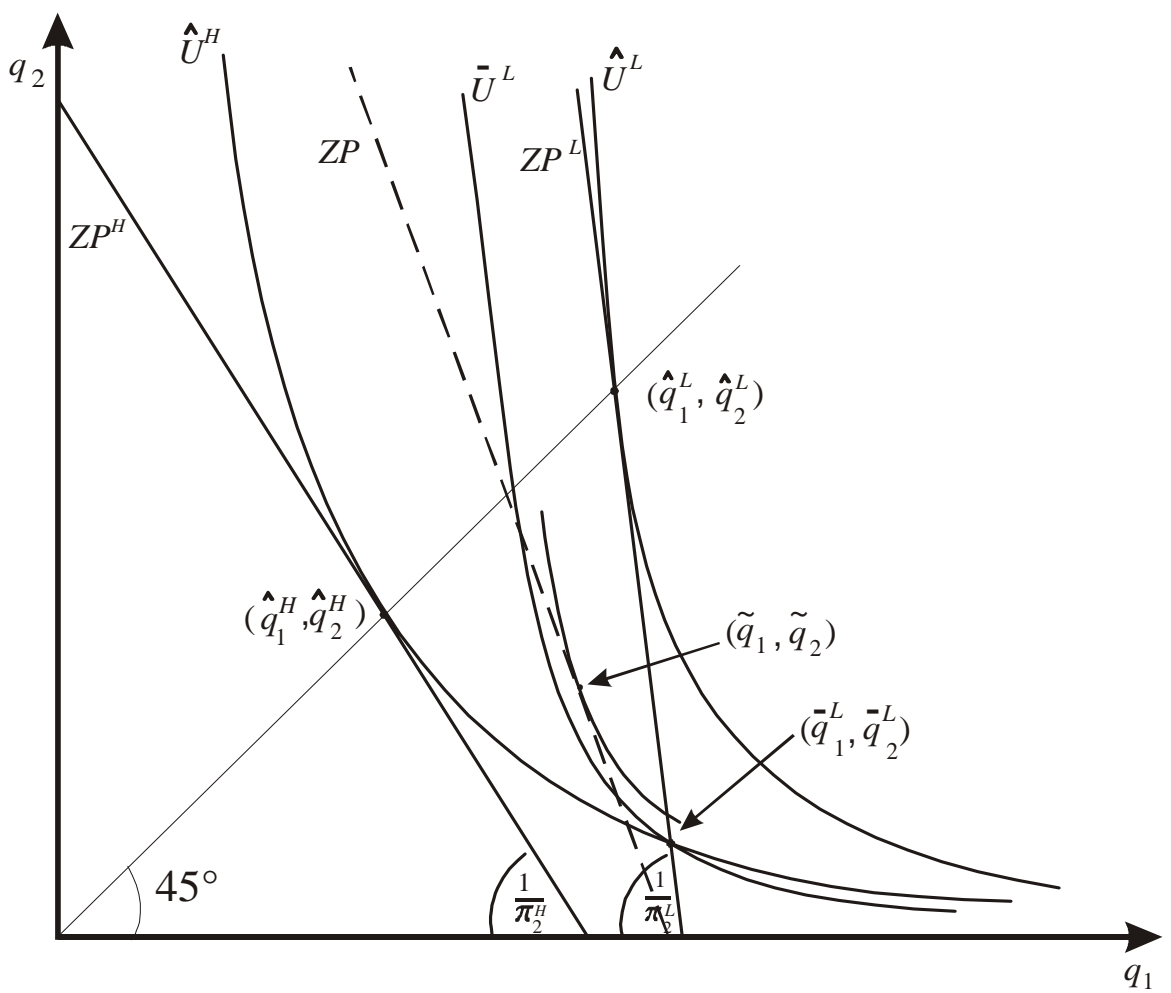

Lemma 6: $\left(\hat{q}_{1}^{H}, \hat{q}_{2}^{H}\right)$ and $\left(\bar{q}_{1}^{L}, \bar{q}_{2}^{L}\right)$ fulfill the self-selection constraints (11) and (12).

As a consequence, the contract set $\left(\hat{q}_{1}^{H}, \hat{q}_{2}^{H}\right)$ and $\left(\bar{q}_{1}^{L}, \bar{q}_{2}^{L}\right)$ is an eligible candidate for a separating equilibrium. Moreover, the next Proposition reveals that this contract set is indeed the only candidate for a separating equilibrium. 
Proposition 2: If a separating equilibrium exists, it consists of the contracts $\left(\hat{q}_{1}^{H}, \hat{q}_{2}^{H}\right)$ and $\left(\bar{q}_{1}^{L}, \bar{q}_{2}^{L}\right)$.

As an intuition for this result, note first that $\left(\hat{q}_{1}^{H}, \hat{q}_{2}^{H}\right)$, the contract which, among all individually fair contracts (i.e. those on $Z P^{H}$ ), is most preferred by type- $H$ individuals, must be part of the equilibrium: Any other contract on $Z P^{H}$ is dominated by $\left(\hat{q}_{1}^{H}, \hat{q}_{2}^{H}\right)$, and firms need not care whether type- $L$ individuals might choose that contract, because this would only increase the profit. However, when offering a specific contract to group $L$, firms have to care that this contract is not chosen by the high-risk individuals, because then they would make a loss. This implies that the self-selection constraint (11) is essential: Among all contracts on $Z P^{L}$, only the one which provides maximum utility for group $L$, subject to the self-selection constraint (11), can be part of a separating equilibrium; this is $\left(\bar{q}_{1}^{L}, \bar{q}_{2}^{L}\right)$. Note, in particular, that $\left(\hat{q}_{1}^{L}, \hat{q}_{2}^{L}\right)$, i.e. the contract on $Z P^{L}$, which is most preferred by the $L$-type individuals, cannot be part of the equilibrium, because it would be preferred by type- $H$ individuals to any contract on $Z P^{H}$.

The properties of the separating equilibrium correspond to familiar findings for other models with asymmetric information: Individuals in the "best" group (in our case: the long-living individuals) can buy their "first-best" contract, while individuals in the other group can only buy a "distorted" contract, in order to keep the former away from buying the contract designed for the latter, i.e. to avoid pooling. In the present framework this means that the payout in the first retirement period is increased at the expense of the payout in the second retirement period, up to a ratio at which the long-living individuals 
switch to purchase their separate contract. Indeed, with $\left(\bar{q}_{1}^{L}, \bar{q}_{2}^{L}\right)$ the ratio $\bar{q}_{1}^{L} / \bar{q}_{2}^{L}$ is sufficiently high that they are not better off than with their most preferred separate contract $\left(\hat{q}_{1}^{H}, \hat{q}_{2}^{H}\right)$, though the latter offers a lower overall return.

It remains to show whether $\left(\hat{q}_{1}^{H}, \hat{q}_{2}^{H}\right)$ and $\left(\bar{q}_{1}^{L}, \bar{q}_{2}^{L}\right)$ indeed represent a separating equilibrium, that is whether any other contract can be offered, which is preferred by at least one group and allows a non-negative profit. One notes first that the arguments which proved that no other pair of contracts constitutes a separating equilibrium also imply that no other separate contracts can be offered which are more favourable for the respective risk-types and produce nonnegative profits. However, $\left(\hat{q}_{1}^{H}, \hat{q}_{2}^{H}\right)$ and $\left(\bar{q}_{1}^{L}, \bar{q}_{2}^{L}\right)$ do not constitute an equilibrium either, if there exists a pooling contract that allows a non-negative profit and is preferred by both groups $i=L, H$.

This argument is demonstrated graphically by means of Figure 2. Consider some pooling contract that lies above the indifference curves $\hat{U}^{H}$ and $\bar{U}^{L}$, but on or below the dashed line $Z P$, which indicates the zero-profit condition (9) for pooling-contracts. (Note that in case of logarithmic utility, ZP is indeed a straight line, since annuity demand $A^{i}$ and thus $\rho$ do not depend on $\left.\left(q_{1}, q_{2}\right)\right)$. Obviously, any such pooling contract, e.g. $\left(\tilde{q}_{1}, \tilde{q}_{2}\right)$, dominates $\left(\hat{q}_{1}^{H}, \hat{q}_{2}^{H}\right),\left(\bar{q}_{1}^{L}, \bar{q}_{2}^{L}\right)$ and produces a non-negative profit. Hence, no separating equilibrium exists. However, the existence of such a pooling contract is less likely, the higher the share $\gamma$ of type- $H$ individuals, because for a higher $\gamma$ the zeroprofit line $Z P$ in Figure 2 simply shifts to the left. If it does not cross $\bar{U}^{L}$, no dominating pooling contract exists. This gives us an intuition for 
Proposition 3: There exists a critical value $\gamma^{*}>0$ of the share of group $H$ such that for any given $\pi_{t}^{i}, t=1,2, i=L, H$, and any $\gamma>\gamma^{*}$ a separating equilibrium exists.

We provide numerical examples for the existence and for the non-existence of a separating equilibrium in Appendix A.3. These calculations show, in addition, that whether or not a separating equilibrium exists, also depends on the difference between the survival probabilities $\pi_{2}^{i}$ of both groups $i=L, H$ in the second retirement period. The existence of a separating equilibrium is more likely, the larger this difference.

Finally note that the qualitative results throughout this section would not change when we assume a discount factor $\alpha<1$ : In this case, for logarithmic utility the slope of the indifference curves is $-q_{2} /\left(\alpha \pi_{2}^{i} q_{1}\right)$ and the most preferred individually fair contract for both risk-groups is the one with $q_{1}^{i}=\alpha q_{2}^{i}$ (apply (7) for logarithmic utility). Consequently, $\left(\hat{q}_{1}^{H}, \hat{q}_{2}^{H}\right)$ and $\left(\hat{q}_{1}^{L}, \hat{q}_{2}^{L}\right)$ lie on a straight line through the origin with slope $\alpha<1$ instead of $\alpha=1$ (see Figure 2). One observes immediately that the arguments for the characterization and the existence of a separating equilibrium remain valid.

Moreover, it should be mentioned that the basic arguments remain valid in case of a general per-period utility function, not just for a logarithmic one, as long as the singlecrossing condition holds. It is straightforward to see that the lines $Z P^{L}$ and $Z P^{H}$, defined by the respective zero-profit conditions for the separate contract for each risk-group, are unaffected by the type of the utility function. Hence the characterization of the 
separating equilibrium remains valid. The main difference is that with a general utility function the dashed curve $Z P$, defined by the zero-profit condition for pooling contracts, will no longer be a straight line, because annuity demand, and the demand ratio $\rho$ in particular, depend on the payoff rates. The shape of $Z P$ in turn has an influence on the existence of the equilibrium.

\subsection{The Wilson equilibrium}

In Subsections 3.1 and 3.2 we have analyzed the existence of Nash-Cournot equilibria. These are defined on the basic assumption that firms, when offering a new contract, take the other firms' contract offers as given. Unfortunately, as we have seen, parameter constellations are possible where no such equilibrium exists. Obviously, the question arises if something more can be said in that case. In the literature (WILSON [1977], RILEY [1979], HeLLWIG [1987]) it is argued that such an unsatisfactory result is the consequence of an incomplete specification of the model (see also MAS-COLELL ET AL. [1995]). In particular, it is the missing consideration of reactions to new contract offers, which is held responsible for the non-existence of an equilibrium.

Following this argument, an interesting approach was suggested by WILSON [1977]: Let a set of existing contracts be offered. A firm, considering a new contract offer, beliefs that existing contracts are not offered any more, if they become unprofitable due to the new contract offer. As a consequence, potential buyers of the existing contracts will turn to the new offer, which influences profitability of the latter. Accordingly, a Wilson pooling equilibrium $\left(q_{1}, q_{2}\right)$ has to fulfill the property that no other contract exists which 
is preferred by at least one group $i=L, H$ and allows a nonnegative profit, given that $\left(q_{1}, q_{2}\right)$ is withdrawn if it becomes unprofitable. The analogous qualification has to be added to the definition of the separating equilibrium in order to describe $a$ Wilson separating equilibrium.

One observes immediately that this qualification makes the definition less restrictive (new contract offers are less attractive). As a consequence, any Nash-Cournot equilibrium is also a Wilson equilibrium. Moreover, we have in case of logarithmic utility (13):

Proposition 4: A Wilson equilibrium exists, even if the separating equilibrium does not exist. It is then a pooling equilibrium, denoted by $\left(\tilde{q}_{1}, \tilde{q}_{2}\right)$, with the following properties:

(i) The zero-profit condition (9) is fulfilled.

(ii) $\left(\tilde{q}_{1}, \tilde{q}_{2}\right)$ is the most preferred pooling contract for the type- $L$ individuals.

Intuitively, the arguments for the non-existence of a Nash-Cournot pooling equilibrium, as explored in Section 3.1, do not apply. The reason is that given $\left(\tilde{q}_{1}, \tilde{q}_{2}\right)$, as defined in Proposition 4 (see also Figure 2), a "new" contract, which is preferred by the low-risk individuals only, turns out to be unprofitable and will not be offered according to Wilson's approach: It would be purchased also by the high-risk individuals due to the withdrawal of $\left(\tilde{q}_{1}, \tilde{q}_{2}\right)$, which, if purchased only by the high-risk group, would cause negative profits. 
Thus, we have found a potential answer to the question of what will be the outcome in case that parameters are such that no separating equilibrium according to the NashCournot assumption exists. (Note, as already mentioned, that the separating equilibrium, if it exists, is also the Wilson equilibrium. $)^{7}$ Numerical examples for a Wilson pooling equilibrium are provided in Appendix A.3. The arguments given at the end of Section 3.2 apply for this section as well: They indicate that the result concerning the Wilson equilibrium remains valid also for a general utility function (not just for logarithmic), as long as the single-crossing condition holds.

\subsection{Equilibria with saving in bonds}

In this section we introduce the possibility of holding one-period bonds and study the implications for the existence of an equilibrium. First we note that, under the assumption of competitive firms, the returns from annuities are necessarily greater than those from bonds, i.e. $q_{1}+q_{2}>1$ (where 1 is the return from bonds for a zero interest rate). ${ }^{8}$ Therefore an individual, who derives no utility from leaving a bequest, always decides to buy some annuities. However, if the ratio $q_{1} / q_{2}$ of annuity payoffs is inadequate, it is optimal for an individual to supplement annuities by bonds in order to smooth consumption appropriately over both retirement periods. If the relative payoff

7 HELLWIG [1987] discusses how these concepts of an equilibrium are related to the modeling to the sequence of moves in the underlying multi-stage game.

8 The result, which goes back to YAARI [1965], holds equivalently for a positive interest rate, because this increases the payoffs $q_{1}, q_{2}$ as well: Like the individuals, insurance companies invest the proceeds (premiums) in bonds and earn interest, until the premiums are paid back to the annuitants. The general intuition, why annuities offer a higher return than bonds, is the following: In case that an individual provides for old-age consumption through bonds, she leaves unintended bequests if dying prematurely. In this case, the deceased's wealth is distributed to the heirs. If, in contrast, the individual puts her wealth into life annuities and dies prematurely, this unconsumed wealth is distributed as annuity 
$q_{1} / q_{2}$ is sufficiently low, it is optimal for the individual in the working period to substitute annuities partly by bonds to increase consumption in the first retirement period. On the other hand, for a sufficiently high relative payoff $q_{1} / q_{2}$, it is optimal for the individual to put money aside from the payoff $q_{1} A^{i}$ in the first retirement period for the second retirement period. For payoff ratios $q_{1} / q_{2}$ in between, the optimal strategy for an individual is to buy annuities only. ${ }^{9,10}$

Our analysis of possible equilibria proceeds along the same lines as before. Obviously, one can still draw indifference curves in the $\left(q_{1}, q_{2}\right)$-space, when holding bonds is included. It is straightforward to see that indifference curves are now flatter at points where holding bonds in period 0 actually occurs, because individuals have an additional instrument to adapt to a small decrease in $q_{1}$, and thus need a smaller increase in $q_{2}$ (compared to a situation where bonds are excluded) in order to stay indifferent. By the same reasoning, the indifference curves are steeper at combinations of $\left(q_{1}, q_{2}\right)$ where saving in bonds in period 1 occurs, compared to a situation where saving in bonds is excluded (because individuals need a smaller increase in $q_{1}$ to compensate for a decrease in $q_{2}$.) For intermediate ratios, where no bonds are held, indifference curves obviously are as in the model without bonds.

payouts to the surviving annuitants. This result holds as long as an annuity company does not have the market power to collect all of the consumer surplus generated in the annuity market.

9 As it is usual, we exclude that individuals can borrow on the capital market, due to the mortality risk.

10 Formal arguments for these properties are provided in Appendix A.2. 
Figure 3

Indifference curves in the model with saving in bonds

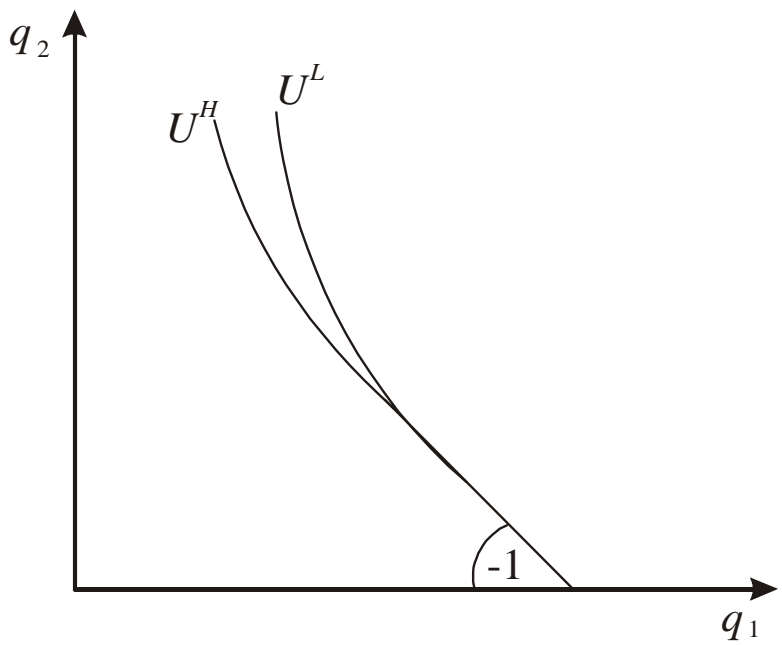

The important observation, relevant for the existence of a (separating) equilibrium is that for large enough $q_{1} / q_{2}$-ratios, such that saving and buying bonds in the first retirement period occurs, indifference curves become straight lines with slope -1 . This is proved in Appendix A.2, but can intuitively be explained by the observation that an individual's utility does not change, if $q_{1}$ is increased by $\Delta q$ and $q_{2}$ is decreased by the same $\Delta q$, because she can fully compensate this change by buying the same amount $A^{i}$ as before and by saving $\Delta q A^{i}$ in period 1 and shifting this amount to the second retirement period: $q_{1}$ and $q_{2}$ are perfect substitutes. Since this applies to any individual, irrespective of her type, i.e. her survival probability, the indifference curves will coincide for sufficiently high payoff ratios. Thus, a situation prevails as shown in Figure 3: Indifference curves coincide for large payoff ratios; the ratio at which type- $H$ individuals start holding bonds is lower than the corresponding one for type- $L$ individuals. This conforms with intuition: Long-living individuals will "sooner" be 
prepared to provide for the second period of retirement by own saving out of firstperiod annuity payouts.

By similar arguments, we find that for sufficiently small $q_{1} / q_{2}$-ratios the indifference curves of both risk-types coincide (with slope $-q_{2} /\left(1-q_{1}\right)$; see Appendix A.2) and that, if the $q_{1} / q_{2}$-ratio is increased, type- $H$ individuals stop at a smaller ratio to supplement annuities by bonds in the working period than the type- $L$ individuals (who have a smaller probability to survive to the second retirement period, hence for them the advantage of annuities over bonds, namely to offer payouts in the second period as well, is less important.). ${ }^{11}$

How does holding bonds affect the existence and characterization of the equilibria? In the following it will be shown that the main results do not change. First, we argue that the negative result concerning the existence of a pooling equilibrium maintains: For any zero-profit pooling contract $\left(q_{1}, q_{2}\right)$ with intermediate ratio $q_{1} / q_{2}$, such that one or both risk-groups invest solely in annuities, we assume, as before, that the single-crossing condition holds, ${ }^{12}$ therefore the arguments of Proposition 1 apply. For any zero-profit pooling contract $\left(q_{1}, q_{2}\right)$, for which the indifference curves of both risk types coincide, i.e. for which both risk-groups hold bonds (either in period 0 or 1), unintended bequests are left by those who die prematurely. It is obvious that in this case one can find another

11 For small $q_{1} / q_{2}$-ratios, where individuals want to shift part of annuity payoffs from period 2 to period 1 , the payoffs $q_{2}$ and $q_{1}$ are not one-to-one substitutes, because individuals cannot borrow on the capital market in period 1; thus shifting involves buying more bonds and less annuities in period 0 . Still, indifference curves are straight lines, as is shown in Appendix A.2. aversion.

12 This is fulfilled for any utility function which exhibits a constant coefficient of relative risk 
pooling contract which makes both groups better off (by avoiding bequests) and allows non-negative profits. Consequently, no pooling equilibrium exists.

Next we investigate the implications of holding bonds on the existence of a separating equilibrium. Again we find the result that a separating equilibrium may, but need not exist, by referring to logarithmic utility and assuming that the discount factor $\alpha$ equals one: We can replicate Figure 2 for the case that individuals are free to buy bonds (see Figure 4).

Figure 4

Equilibria in the model with saving in bond

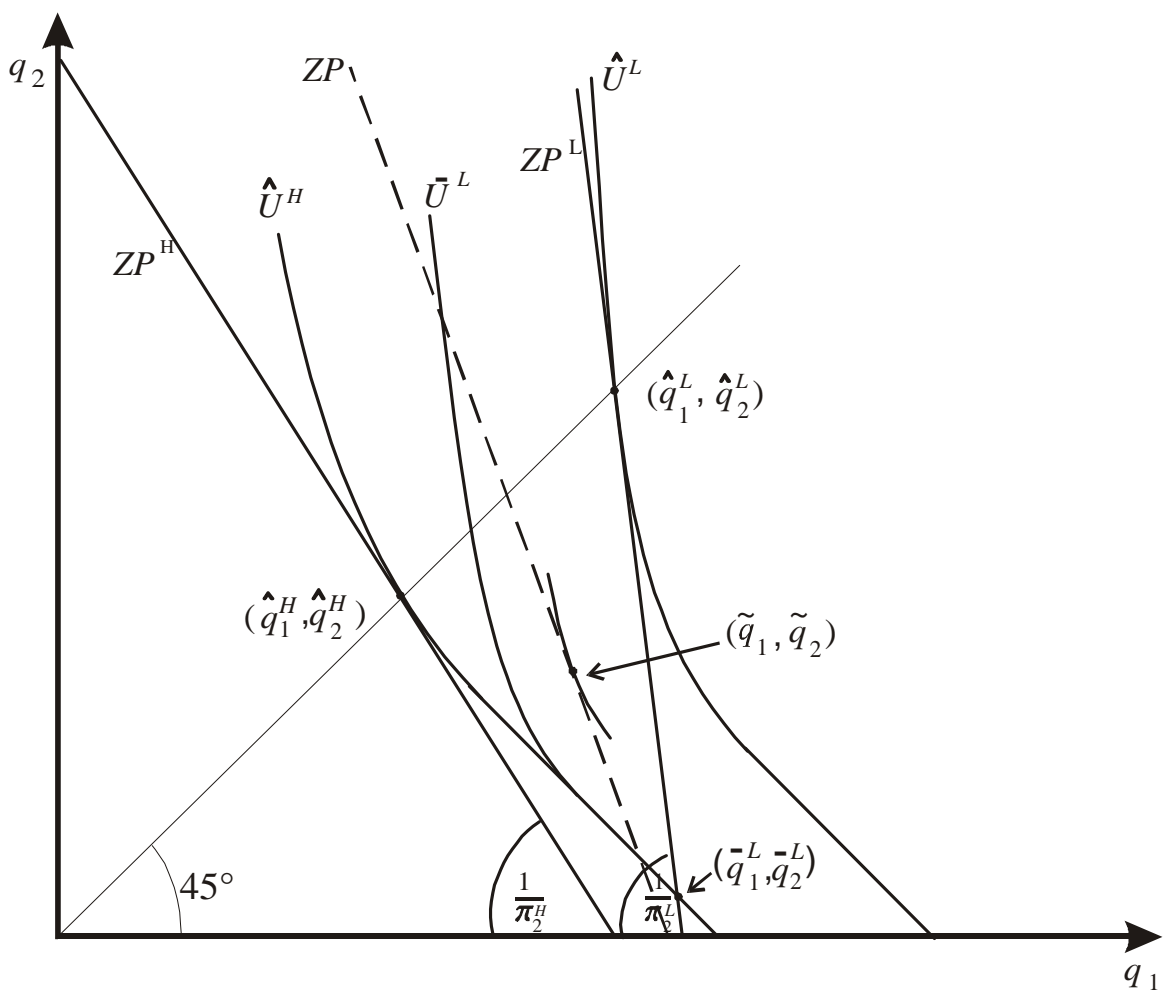


Note that for logarithmic utility the indifference curves of group $i$ are convex with slope $-q_{2} /\left(1-q_{1}\right)$ for any $q_{1} \leq 1 /\left(1+\pi_{2}^{i}\right)$, slope $-q_{2} /\left(\pi_{2}^{i} q_{1}\right)$ for any $1 /\left(1+\pi_{2}^{i}\right)<q_{1}<q_{2} / \pi_{2}^{i}$ and slope -1 for any $q_{1} \geq q_{2} / \pi_{2}^{i}$ (see Appendix A.2). The two contracts $\left(\hat{q}_{1}^{H}, \hat{q}_{2}^{H}\right)$ and $\left(\bar{q}_{1}^{L}, \bar{q}_{2}^{L}\right)$, which may represent a represent a separating equilibrium, are defined as in Section 3.2. At their most preferred individually fair contract $\left(\hat{q}_{1}^{H}, \hat{q}_{2}^{H}\right)$, it is never attractive for high-risk individuals to save in the first retirement period, as shown in Appendix A.2. But this may be the case for low-risk individuals, in case that $\left(\bar{q}_{1}^{L}, \bar{q}_{2}^{L}\right)$ is offered to them: The ratio $\bar{q}_{1}^{L} / \bar{q}_{2}^{L}$ may be large enough that buying bonds in the first period of retirement is optimal. Such a situation is drawn in Figure 4. In this case the arguments explored in Section 3.2 for the model without saving apply: It depends on the position of the zero-profit line for a pooling contract whether or not $\left(\hat{q}_{1}^{H}, \hat{q}_{2}^{H}\right)$ and $\left(\bar{q}_{1}^{L}, \bar{q}_{2}^{L}\right)$ constitute a separating equilibrium, because both may be dominated by $\left(\tilde{q}_{1}, \tilde{q}_{2}\right)$, as drawn in Figure 4.

Note, however, that there can be situations where no contract $\left(\bar{q}_{1}^{L}, \bar{q}_{2}^{L}\right)$ with $\bar{q}_{1}^{L}>\bar{q}_{2}^{L}$ exists, which lies on the zero-profit line $Z P^{L}$ for group $L$ and leaves the high-risk individuals indifferent to $\left(\hat{q}_{1}^{H}, \hat{q}_{2}^{H}\right)$. Then any individually fair contract for group $L$ with $q_{1}^{L}>q_{2}^{L}$ would make the high-risk individuals better off. Thus we have found a further reason for the non-existence of a separating equilibrium. Such a situation will prevail, if the zero-profit lines of group $H$ and group $L$ are sufficiently remote, which may be the case for a large difference in the survival probabilities of both groups. 
Finally, it should be mentioned that the arguments for the existence of a Wilson equilibrium (given in Section 3.3) remain valid also in the model with holding bonds. Even if a separating equilibrium does not exist, the pooling contract $\left(\tilde{q}_{1}, \tilde{q}_{2}\right)$, defined as in Proposition 4, constitutes a Wilson equilibrium. Again we give numerical examples for the existence of a separating equilibrium and for a Wilson pooling equilibrium in case of the non-existence of a separating equilibrium in the Appendix A.3.

\section{Concluding remarks}

Considering a life-cycle model with more than one period of retirement allows the formulation of an additional important aspect of the annuity market: It is an attractive strategy for companies to offer annuity contracts, for which the pension payoffs are not constant over the periods of retirement, since individuals with different life expectancies will put different weights on the payment they may or may not receive in the last period of life. In the present study we have analyzed the consequence of this possibility on the existence of equilibria in the private annuity market under price competition and asymmetric information. Our main finding was that in this framework a Nash-Cournot equilibrium may not exist; if one exists, it will be a separating equilibrium. On the other hand, even if a separating equilibrium does not exist, a Wilson pooling equilibrium exists.

By assuming only one period of retirement, previous studies have neglected the fact that the time structure of the payoffs matters, which has led to the conclusion that under price competition and adverse selection a pooling equilibrium always exists. So, when 
concentrating on the fact that in real life annuities provide periodic payouts over the time of retirement, one can conclude that the existence of a stable outcome is less likely than it has been supposed so far.

An interesting question is whether the existence of the equilibrium is affected by the introduction of a public pension system. Obviously, this depends on the size of the obligatory contribution rates. If it is sufficiently small, nothing changes. To find out the effects of larger rates, we ran numerical simulations (reported in Appendix A.3), where a funded system with a fixed contribution for every individual and constant payoffs (over time) according to the average life-expectancy of the population was added into the model of this paper. It turned out that the introduction of a public pension system did not destroy the existence of the separating equilibrium. Further, for a certain range of parameter values, a separating equilibrium emerged, even if it did not without the public pension system. In this case the public pension system can give rise to a Paretoimprovement.

A consequence of our extended model is that it should change the view guiding empirical studies. Usually, they start from the premise that the annuity market should ideally offer a pooling contract for all risks, and study the adverse-selection phenomenon by comparing life-expectancy of annuity purchasers with the average lifeexpectancy of the population. By looking at a specific annuity contract, the magnitude of adverse selection is measured by the difference between the expected rate of return for the general population and the expected rate of return for the subpopulation of 
annuitants. ${ }^{13}$ Instead, our result suggests that a primary object of investigation should be the question of whether separating indeed occurs and to which extent. As already mentioned in the Introduction, there is empirical evidence for the UK that selection effects across different types of annuity contracts, characterized by different time paths of the payouts indeed exists (FINKELSTEIN AND POTERBA [2002, 2004]).

Given the problem of asymmetric information, the selection of risks through an appropriate time-structure of the payoffs is only one alternative among various possible others. In principle, selection can occur across all the different types of annuity contracts that are offered. For instance, as discussed in the Introduction, the length of the period covered by term-insured contracts acts as a selection instrument (TOWNLEY AND BOADWAY [1988]), as do other parameters like a guaranteed minimum payoff period (to the advantage of a beneficiary) or the age at which the annuity is purchased (FInKelstein AND Poterba [2002]). Obviously, the best method to overcome the adverse-selection problem would be for an insurance company to collect more information related to life-expectancy of the customers, e.g. some characteristics of the socio-economic status (as is well-known, a better status corresponds with longer life expectancy) or even a health test. In fact, FINKELSTEIN AND PoTERBA [2002] report that a minority of firms in the UK offer a discount for smokers or for people living in a region with high mortality, but by far the majority collects only information about gender and age. However, one might expect firms to change their behaviour and develop additional instruments in the future. [1999].

13 See, e.g., FrIEDMAN AND WARShAWSKY [1988, 1990], WALLISER [2000], MitChELL ET AL. 
Private annuity insurance is becoming more important, because of the expected decline of the replacement ratio offered by the public pension system in many countries. Our contribution adds to the set of studies expressing doubts on the adequate functioning of the annuity market. Clarifying this issue further, appears to be a prominent task for future theoretical and empirical research.

\section{Appendix}

\section{A.1. Proofs}

Proof of Lemma 1: We determine $\partial A^{i} / \partial \pi_{t}^{i}, t=1,2$, by implicit differentiation of the first-order condition for annuity demand, $\partial U^{i} / \partial A^{i}=0$, with respect to $\pi_{t}^{i}$ as $-\left(\partial^{2} U^{i} / \partial A^{i} \partial \pi_{t}^{i}\right) /\left(\partial^{2} U^{i} / \partial A^{i} \partial A^{i}\right)$. Since the denominator is negative due to the secondorder condition of the maximization problem, and the numerator for $t=1,2$, is (use (1) (3) and (4')) equal to

$$
\begin{aligned}
& \partial^{2} U^{i} / \partial A^{i} \partial \pi_{1}^{i}=\alpha q_{1} u^{\prime}\left(q_{1} A^{i}\right)+\pi_{2}^{i} \alpha^{2} q_{2} u^{\prime}\left(q_{2} A^{i}\right), \\
& \partial^{2} U^{i} / \partial A^{i} \partial \pi_{2}^{i}=\pi_{1}^{i} \alpha^{2} q_{2} u^{\prime}\left(q_{2} A^{i}\right),
\end{aligned}
$$

which are both positive, $\partial A^{i} / \partial \pi_{t}^{i}, t=1,2$, are both positive too. Hence $A^{H}>A^{L}$. Q.E.D.

Proof of Lemma 2: We maximize lifetime utility (4') with respect to $q_{1}^{i}$ and $q_{2}^{i}$, subject to (6). Using (2) and (3), the first-order conditions of this problem are 


$$
\pi_{1}^{i} \alpha A^{i} u^{\prime}\left(c_{1}^{i}\right)+\lambda \pi_{1}^{i}=0
$$

$$
\pi_{1}^{i} \pi_{2}^{i} \alpha^{2} A^{i} u^{\prime}\left(c_{2}^{i}\right)+\lambda \pi_{1}^{i} \pi_{2}^{i}=0
$$

where $\lambda$ is the Lagrange multiplier associated with the constraint (6). From (A2) and (A3), we find that maximization requires (7). From (7) one concludes that $c_{1}^{i}>c_{2}^{i}$, if $\alpha<1$, and $c_{1}^{i}=c_{2}^{i}$, if $\alpha=1$. This in turn implies, together with (2) and (3), that for any arbitrarily given $A^{i}, q_{1}^{i}>q_{2}^{i}$, if $\alpha<1$, and $q_{1}^{i}=q_{2}^{i}$, if $\alpha=1$.

Q.E.D.

Proof of Lemma 3: Substituting (2) and (3) into (4') we get (apply the Envelope Theorem)

$$
\frac{\partial U^{i}}{\partial q_{1}}=\pi_{1}^{i} \alpha A^{i} u^{\prime}\left(c_{1}^{i}\right)+\pi_{1}^{i} \pi_{2}^{i} \alpha^{2} A^{i} \frac{d q_{2}}{d q_{1}} u^{\prime}\left(c_{2}^{i}\right)
$$

By use of (7), it follows that

$$
\frac{\partial U^{i}}{\partial q_{1}}=\pi_{1}^{i} \alpha A^{i} u^{\prime}\left(c_{1}^{i}\right)\left(1+\pi_{2}^{i} \frac{d q_{2}}{d q_{1}}\right) .
$$

(A5) shows that the sign of $\partial U^{i} / \partial q_{1}$ depends on the sign of $1+\pi_{2}^{i} d q_{2} / d q_{1}$. Implicit differentiation of the zero-profit condition (9') gives 


$$
\frac{d q_{2}}{d q_{1}}=-\frac{\left(1-q_{1} \pi_{1}^{H}-q_{2} \pi_{1}^{H} \pi_{2}^{H}\right) \frac{\partial \rho}{\partial q_{1}}-\left(\pi_{1}^{L}+\rho \pi_{1}^{H}\right)}{\left(1-q_{1} \pi_{1}^{H}-q_{2} \pi_{1}^{H} \pi_{2}^{H}\right) \frac{\partial \rho}{\partial q_{2}}-\left(\pi_{1}^{L} \pi_{2}^{L}+\rho \pi_{1}^{H} \pi_{2}^{H}\right)} .
$$

Obviously, the assumption of a fixed ratio $\rho$ of annuity demand implies $\partial \rho / \partial q_{t}=0$, $t=1$,2. Thus, for fixed $\rho, \pi_{2}^{i} d q_{2} / d q_{1}$ reduces to $-\pi_{2}^{i}\left(\pi_{1}^{L}+\rho \pi_{1}^{H}\right) /\left(\pi_{1}^{L} \pi_{2}^{L}+\rho \pi_{1}^{H} \pi_{2}^{H}\right)$, which is smaller than -1 for $i=H$, and greater than -1 for $i=L$. As a consequence, the RHS in (A5) is negative for $i=H$ and positive for $i=L$, which proves the Lemma.

Q.E.D.

Proof of Lemma 4: $d A^{i} / d q_{1}$ is determined by implicit differentiation of the first-order condition for annuity demand, $\partial U^{i} / \partial A^{i}=0$, with respect to $q_{1}$ as

$$
\frac{d A^{i}}{d q_{1}}=-\frac{\partial^{2} U^{i} / \partial A^{i} \partial q_{1}}{\partial^{2} U^{i} / \partial^{2} A^{i}}
$$

Since the denominator of the RHS of (A7) is negative due to the second-order condition of the maximization problem, $d A^{i} / d q_{1}$ has the same sign as the numerator of the RHS of (A7).

Substituting (1), (2) and (3) into (4') we obtain

$$
\frac{\partial^{2} U^{i}}{\partial A^{i} \partial q_{1}}=\pi_{1}^{i} \alpha\left(u^{\prime}\left(c_{1}^{i}\right)+q_{1} A^{i} u^{\prime \prime}\left(c_{1}^{i}\right)\right)+\pi_{1}^{i} \pi_{2}^{i} \alpha^{2} \frac{d q_{2}}{d q_{1}}\left(u^{\prime}\left(c_{2}^{i}\right)+q_{2} A^{i} u^{\prime \prime}\left(c_{2}^{i}\right)\right) .
$$


If $c_{1}^{i}=c_{2}^{i}$ (in case of $\alpha=1$ ) or if $R$ is independent of $c_{t}^{i}$, (A8) can be transformed to (note (7))

$$
\frac{\partial^{2} U^{i}}{\partial A^{i} \partial q_{1}}=\pi_{1}^{i} \alpha\left(1+\pi_{2}^{i} \frac{d q_{2}}{d q_{1}}\right) u^{\prime}\left(c_{1}^{i}\right)(1-R)
$$

If $R=1$, then (A9) and thus (A7) are zero for individuals of both types $i=L, H$. Otherwise we determine, as in the proof of Lemma $3, d q_{2} / d q_{1}$ from the zero-profit condition (9') and find that for a fixed ratio $\rho$ of annuity demand $\pi_{2}^{H} d q_{2} / d q_{1}<-1$ and $\pi_{2}^{L} d q_{2} / d q_{1}>-1$. Thus, in case that $R<1$, (A9) is negative for $i=H$ and positive for $i=L$. The opposite is true for $R>1$.

Proof of Lemma 5: As $1-q_{1} \pi_{1}^{L}-q_{2} \pi_{1}^{L} \pi_{2}^{L}>0$ for any pooling contract $\left(q_{1}, q_{2}\right)$, which fulfills the zero-profit condition (9), the profit for an insurance company is positive, given that only this group chooses the contract $\left(q_{1}, q_{2}\right)$. By continuity, this holds for any contract $\left(q_{1}+\delta q_{1}, q_{2}+\delta q_{2}\right)$ in the neighbourhood of $\left(q_{1}, q_{2}\right)$.

Q.E.D.

Proof of Proposition 1: Let some contract $\left(q_{1}, q_{2}\right)$ with associated $A^{i}\left(q_{1}, q_{2}\right), i=L, H$, be given, such that the zero-profit condition (9) is fulfilled. We find the effect $\delta U^{i}$ of a marginal change $\left(\delta q_{1}, \delta q_{2}\right)$ of the contract on group i's utility as

$$
\delta U^{i}=\frac{\partial U^{i}}{\partial q_{1}} \delta q_{1}+\frac{\partial U^{i}}{\partial q_{2}} \delta q_{2}, \quad i=L, H
$$


The single-crossing condition implies that the RHS's of the two equations (A10) are linearly independent (i.e. there is no $k$ such that $\partial U^{L} / \partial q_{1}=k \partial U^{H} / \partial q_{1}$ and $\partial U^{L} / \partial q_{2}=k \partial U^{H} / \partial q_{2}$ ), hence the two equations (A10) have a unique solution. Choosing some $\delta U^{L}>0, \delta U^{H}<0$ and solving (A10) for $\delta q_{1}, \delta q_{2}$, one finds a new contract $\left(q_{1}+\delta q_{1}, q_{2}+\delta q_{2}\right)$, which is preferred by group $L$, but not by group $H$. By Lemma 5, it also allows a non-negative profit. (As $\delta U^{L}$ and $\delta U^{H}$ can be chosen arbitrarily close to zero, $\delta q_{1}$ and $\delta q_{2}$ can be taken as arbitrarily close to zero as well.) Hence $\left(q_{1}, q_{2}\right)$ is not a pooling equilibrium. Q.E.D.

Proof of Lemma 6: (11) is fulfilled by definition. That (12) is satisfied follows from $\bar{q}_{1}^{L}>\bar{q}_{2}^{L}$, from the fact that $\left(\hat{q}_{1}^{H}, \hat{q}_{2}^{H}\right)$ and $\left(\bar{q}_{1}^{L}, \bar{q}_{2}^{L}\right)$ are on the same indifference curve for a type- $H$ individual and that the slope of the indifference curve through $\left(\bar{q}_{1}^{L}, \bar{q}_{2}^{L}\right)$ is steeper for a type- $L$ individual than for a type- $H$ individual (see Figure 2). $\quad$ Q.E.D.

Proof of Proposition 2: Note first that, if $\left(\hat{q}_{1}^{H}, \hat{q}_{2}^{H}\right)$ is part of the separating equilibrium, then $\left(\bar{q}_{1}^{L}, \bar{q}_{2}^{L}\right)$ must be the other part, because it provides maximum utility for group $L$, subject to the self-selection constraint (11) for group $H$ and to the zero-profit condition for (6) for $i=L$. With $\left(\bar{q}_{1}^{L}, \bar{q}_{2}^{L}\right)$ and $\left(\hat{q}_{1}^{H}, \hat{q}_{2}^{H}\right)$, (11) is fulfilled with equality. (Note from Figure 2 that the second point of intersection of $\hat{U}^{H}$ and $Z P^{L}$, as mentioned in the text, as well as all contracts on $Z P^{L}$ above this point of intersection, and also those below $\left(\bar{q}_{1}^{L}, \bar{q}_{2}^{L}\right.$ ), fulfill (11). However, they all provide lower utility for group $L$; remember the 
single-crossing property.) Furthermore, one observes that, for the same reason, if any other contract $\left(q_{1}^{\prime H}, q_{2}^{\prime H}\right.$ ) on $Z P^{H}$ is part of a separating equilibrium, then the other part, the separate contract for group $L$, must be that pair of payoffs $\left(q_{1}^{\prime L}, q_{2}^{\prime L}\right)$, which are found as the point of intersection of $Z P^{L}$ and the indifference curve of group $H$ through $\left(q_{1}^{\prime H}, q_{2}^{\prime H}\right)$, where $q_{1}^{\prime L}>q_{2}^{\prime L}$. Obviously, group $H$ prefers $\left(\hat{q}_{1}^{H}, \hat{q}_{2}^{H}\right)$ to any other $\left(q_{1}^{\prime H}, q_{2}^{\prime H}\right)$ and group $L$ prefers $\left(\bar{q}_{1}^{L}, \bar{q}_{2}^{L}\right)$ to any other $\left(q_{1}^{\prime L}, q_{2}^{\prime L}\right)$.

Q.E.D.

Proof of Proposition 3: As mentioned in the text, a variation of the group share $\gamma$ only influences the zero-profit condition (9) for a pooling contract, while leaving the zeroprofit condition (6) for separating contracts (and the indifference curves, of course) unchanged. Comparison of (9) and (6) shows that the zero-profit condition (9) for a pooling contract converges to the zero-profit condition (6) for group $H$, if $\gamma$ approaches one. We have already seen that group $L$ prefers $\left(\bar{q}_{1}^{L}, \bar{q}_{2}^{L}\right)$ to any contract on $Z P^{H}$ (note the single-crossing condition). By continuity, group $L$ prefers $\left(\bar{q}_{1}^{L}, \bar{q}_{2}^{L}\right)$ to any contract fulfilling the zero-profit condition for a pooling contract, as long as $\gamma$ is sufficiently close to 1 . In that case, no pooling contract can make a non-negative profit, because it is chosen only by the high-risk individuals. We define $\gamma^{*}$ as the infinum of all $\gamma$, for which group $L$ prefers $\left(\bar{q}_{1}^{L}, \bar{q}_{2}^{L}\right)$ to any pooling contract. On the other hand, analogous considerations show that for sufficiently small $\gamma$, a profitable pooling contract, which dominates $\left(\hat{q}_{1}^{H}, \hat{q}_{2}^{H}\right)$ and $\left(\bar{q}_{1}^{L}, \bar{q}_{2}^{L}\right)$, always exists.

Q.E.D. 
Proof of Proposition 4: The proof is derived from geometric arguments (see Figure 2). Consider the pooling contract $\left(\tilde{q}_{1}, \tilde{q}_{2}\right)$. We show that no firm has an incentive to deviate from $\left(\tilde{q}_{1}, \tilde{q}_{2}\right)$ : In case that a contract $\left(\tilde{q}_{1}+\delta q_{1}, \tilde{q}_{2}+\delta q_{2}\right)$ is offered which is preferred by the low-risk, but not by the high-risk individuals (compare Figure 1), the original contract $\left(\tilde{q}_{1}, \tilde{q}_{2}\right)$, being then purchased by the high-risk individuals only, makes negative profits and will be withdrawn from the market. Consequently, the type- $H$ individuals will also accept the contract $\left(\tilde{q}_{1}+\delta q_{1}, \tilde{q}_{2}+\delta q_{2}\right)$, which therefore will turn out to be unprofitable (note that $\left(\tilde{q}_{1}+\delta q_{1}, \tilde{q}_{2}+\delta q_{2}\right)$, if preferred by the low-risk individuals, must lie to the right of the zero-profit line ZP for pooling contracts) and will not be offered. As a result, $\left(\tilde{q}_{1}, \tilde{q}_{2}\right)$ is a Wilson pooling equilibrium.

Q.E.D.

\section{A.2 The decision problem in the model with saving in bonds}

In case that an individual $i$ is free to buy annuities and one-period bonds, the budget equations in the three periods $t=0,1,2$, read (Remember that a zero-interest rate is assumed)

$$
\begin{aligned}
& c_{0}^{i}=w-A^{i}-K^{i}, \\
& c_{1}^{i}=q_{1} A^{i}+K^{i}-S^{i}, \\
& c_{2}^{i}=q_{2} A^{i}+S^{i},
\end{aligned}
$$

where $K^{i}$ denotes savings in bonds in the working period and $S^{i}$ savings in bonds in the first retirement period. As mentioned in the main text, we exclude borrowing, hence $K^{i}, S^{i} \geq 0$. Substituting (A11) - (A13) into (4') and differentiating with respect to $A^{i}, K^{i}$, 
and $S^{i}$, we obtain the Kuhn-Tucker conditions of this maximization problem as (5) in the main text and additionally

$$
\begin{aligned}
& A^{i}=0 \text { and }-u^{\prime}\left(c_{o}^{i}\right)+\pi_{1}^{i} \alpha q_{1} u^{\prime}\left(c_{1}^{i}\right)+\pi_{1}^{i} \pi_{2}^{i} \alpha^{2} q_{2} u^{\prime}\left(c_{2}^{i}\right) \leq 0 \\
& K^{i}>0 \text { and }-u^{\prime}\left(c_{0}^{i}\right)+\pi_{1}^{i} \alpha u^{\prime}\left(c_{1}^{i}\right)=0, \\
& K^{i}=0 \text { and }-u^{\prime}\left(c_{0}^{i}\right)+\pi_{1}^{i} \alpha u^{\prime}\left(c_{1}^{i}\right) \leq 0 . \\
& S^{i}>0 \text { and }-\pi_{1}^{i} \alpha u^{\prime}\left(c_{1}^{i}\right)+\pi_{1}^{i} \pi_{2}^{i} \alpha^{2} u^{\prime}\left(c_{2}^{i}\right)=0, \\
& S^{i}=0 \text { and }-\pi_{1}^{i} \alpha u^{\prime}\left(c_{1}^{i}\right)+\pi_{1}^{i} \pi_{2}^{i} \alpha^{2} u^{\prime}\left(c_{2}^{i}\right) \leq 0 .
\end{aligned}
$$

Note first that the conditions (5), (A15) and (A17) for the interior optima do not hold simultaneously, given that $q_{1}+q_{2}>1$ (as argued in Section 3.4): Substituting (A15) and (A17) into (5) yields $\left(-1+q_{1}+q_{2}\right) \pi_{1}^{i} \alpha u^{\prime}\left(c_{1}^{i}\right)=0$, which is only fulfilled if $q_{1}+q_{2}=1$. (In this case, the individuals would be indifferent between savings in bonds and annuities to provide for retirement, because annuities and bonds yield the same returns.) Moreover, the case that $A^{i}=0$ can be excluded: Then $K^{i}>0$ and $S^{i}>0$ must hold to ensure positive consumption levels in both retirement periods. Using (A14), (A15) and (A17) yields $\left(-1+q_{1}+q_{2}\right) \pi_{1}^{i} \alpha u^{\prime}\left(c_{1}^{i}\right) \leq 0$, which is fulfilled only if $q_{1}+q_{2}<1$.

Hence, the cases $A^{i}>0$ and either $K^{i}>0$ or $S^{i}>0$ (but not both) or $K^{i}=S^{i}=0$ remain, where obviously $K^{i}>0$ occurs for sufficiently small payoff ratios $q_{1} / q_{2}$ and $S^{i}>0$ occurs for sufficiently large payoff ratios $q_{1} / q_{2}$. One can show by (a bit tedious) implicit differentiation of (5) and (A15) that for small $q_{1} / q_{2}$, such that $K^{i}>0, K^{i}$ 
decreases along an indifference curve in the $\left(q_{1}, q_{2}\right)$-space with increasing $q_{1} / q_{2}$-ratio, while implicit differentiation of (5) and (A17) shows that for large $q_{1} / q_{2}$, such that $S^{i}>0, S^{i}$ increases along an indifference curve. Hence, as not both are positive simultaneously, $K^{i}$ and $S^{i}$ are zero for intermediate values of $q_{1} / q_{2}$. Specifically we show that it is optimal for an individual to choose $A^{i}>0, K^{i}=0$ and $S^{i}=0$ at her most preferred individually fair contract $\left(q_{1}, q_{2}\right)$ determined by (7): Substituting (7) into the condition (A18) for the boundary optimum $S^{i}=0$ yields

$$
\left(-1+\pi_{2}^{i}\right) \pi_{1}^{i} \alpha u^{\prime}\left(q_{1} A^{i}\right) \leq 0
$$

which is strictly fulfilled, as $\pi_{2}^{i}<1$. By use of condition (5) for the interior optimum $A^{i}>0$ and of the condition (A16) for the boundary optimum $K^{i}=0$, one obtains

$$
\left(-1+q_{1}\right) \pi_{1}^{i} \alpha u^{\prime}\left(q_{1} A^{i}\right)+\pi_{1}^{i} \pi_{2}^{i} \alpha^{2} q_{2} u^{\prime}\left(q_{2} A^{i}\right) \geq 0 .
$$

Substituting (7) and the zero-profit condition (6) into (A20) gives

$$
\left(-1+\pi_{1}^{i}\right) \alpha u^{\prime}\left(q_{1} A^{i}\right) \geq 0,
$$

which is strictly fulfilled, as $\pi_{1}^{i}<1$. 
Remember from Section 3.1 that the slope $\left(-\partial U^{i} / \partial q_{1}\right) /\left(\partial U^{i} / \partial q_{2}\right)$ of an indifference curve in the $\left(q_{1}, q_{2}\right)$-space is just given by $-u^{\prime}\left(c_{1}^{i}\right) /\left(\pi_{2}^{i} \alpha u^{\prime}\left(c_{2}^{i}\right)\right)$. Rearrangement of (A17) to

$$
\frac{u^{\prime}\left(q_{1} A^{i}-S^{i}\right)}{\pi_{2}^{i} \alpha u^{\prime}\left(q_{2} A^{i}+S^{i}\right)}=1
$$

shows that the slope is equal to -1 for those $q_{1} / q_{2}$-ratios, at which $S^{i}>0$. Equivalently, it follows from (use (5) together with (A15))

$$
\frac{u^{\prime}\left(q_{1} A^{i}+K^{i}\right)}{\pi_{2}^{i} \alpha u^{\prime}\left(q_{2} A^{i}\right)}=\frac{q_{2}}{1-q_{1}}
$$

that the slope of the indifference curve is equal to $-q_{2} /\left(1-q_{1}\right)$ for those $q_{1} / q_{2}$-ratios, at which $K^{i}>0$.

Moreover, if we start from some pair $\left(0, q_{2}^{0}\right)$ - where only the second-period payoff is positive, and with associated optimal values $K_{0}^{i}>0$ and $A_{0}^{i}>0$, then unchanged consumption in all three periods, given an increase in $q_{1}$, requires that new values $K_{1}^{i}$, $A_{1}^{i}$ and $q_{2}$ fulfil $K_{0}^{i}+A_{0}^{i}=K_{1}^{i}+A_{1}^{i}, K_{0}^{i}=K_{1}^{i}+q_{1} A_{1}^{i}, q_{2}^{0} A_{0}^{i}=q_{2} A_{1}^{i}$. Solving this system gives $q_{2}=q_{2}^{0}\left(1-q_{1}\right)$, that is, indifference curves are straight lines with slope $-q_{2}^{0}=-q_{2} /\left(1-q_{1}\right)$, as long as $K^{i}$ is positive. 
Finally, for logarithmic utility (see (13)) we obtain, by use of (A18), that $S^{i}=0$ if $q_{1} \leq q_{2} /\left(\pi_{2}^{i} \alpha\right)$ and, by use of (A20), that $K^{i}=0$ if $q_{1} \geq 1 /\left(1+\pi_{2}^{i} \alpha\right)$. From this and the considerations above it follows that for logarithmic utility the indifference curves of group i are convex with slope $-q_{2} /\left(1-q_{1}\right)$ for any $q_{1}<1 /\left(1+\pi_{2}^{i} \alpha\right)$, slope $-q_{2} /\left(\pi_{2}^{i} q_{1}\right)$ for any $1 /\left(1+\pi_{2}^{i} \alpha\right) \leq q_{1} \leq q_{2} /\left(\pi_{2}^{i} \alpha\right)$ and slope -1 for any $q_{1}>q_{2} /\left(\pi_{2}^{i} \alpha\right)$.

\section{A.3 Numerical illustration of the (non-)existence of separating equilibria.}

(a) Model without Saving in Bonds: For logarithmic utility (see (13)), annuity demand is computed from (5), (1) - (3) as

$$
A^{i}=\frac{\pi_{1}^{i}\left(1+\pi_{2}^{i}\right)}{1+\pi_{1}^{i}\left(1+\pi_{2}^{i}\right)} w,
$$

which is independent from the rates of return $\left(q_{1}, q_{2}\right)$, as mentioned in the text.

The separate contracts $\left(\hat{q}_{1}^{H}, \hat{q}_{2}^{H}\right)$ and $\left(\bar{q}_{1}^{L}, \bar{q}_{2}^{L}\right)$ are computed as follows: Solving the zero- profit condition (6) for $i=H$ and setting $q_{1}^{H}=q_{2}^{H}$ yields

$$
\hat{q}_{1}^{H}=\frac{1}{\pi_{1}^{H}\left(1+\pi_{2}^{H}\right)} .
$$


The contract $\left(\bar{q}_{1}^{L}, \bar{q}_{2}^{L}\right)$ for type- $L$ individual, is determined by the self-selection constraint (11), and the zero-profit-condition (6) for $i=L$. Assuming equality, one derives from (11) (making use of (A24), (A25), (2), (3) and (13))

$$
\left(q_{1}^{L}\right)^{\left(1+\pi_{2}^{H}\right) / \pi_{2}^{H}}-\frac{1}{\pi_{1}^{L}}\left(q_{1}^{L}\right)^{1 / \pi_{2}^{H}}+\pi_{2}^{L}\left(\hat{q}_{1}^{H}\right)^{\left(1+\pi_{2}^{H}\right) / \pi_{2}^{H}}=0
$$

(A26) can be solved to compute $\bar{q}_{1}^{L}$, then $\bar{q}_{2}^{L}$ follows from (6).

In order to proof that the contracts $\left(\hat{q}_{1}^{H}, \hat{q}_{2}^{H}\right)$ and $\left(\bar{q}_{1}^{L}, \bar{q}_{2}^{L}\right)$ indeed constitute an equilibrium, we have to show that there is no pooling contract which fulfills the zeroprofit condition ( $\left.9^{\prime}\right)$ and is preferred by individuals of both types $i=L, H$. To do so, we concentrate on the pooling contract $\left(\tilde{q}_{1}, \tilde{q}_{2}\right)$ which together with (A24) fulfils the zeroprofit condition (9') and which is preferred most by a type- $L$ individual. This is the accurate procedure, since an individual of type $H$ is certainly better off with the pooling contract $\left(\tilde{q}_{1}, \tilde{q}_{2}\right)$ than with her own contract $\left(\hat{q}_{1}^{H}, \hat{q}_{2}^{H}\right)$, given a type- $L$ individual prefers $\left(\tilde{q}_{1}, \tilde{q}_{2}\right)$ to $\left(\bar{q}_{1}^{L}, \bar{q}_{2}^{L}\right)$. Maximization of $(13)$ for $i=L$ subject to $\left(9^{\prime}\right)$ gives

$$
\tilde{q}_{1}=\frac{1+\rho}{\left(1+\pi_{2}^{L}\right)\left(\pi_{1}^{L}+\rho \pi_{1}^{H}\right)}, \quad \tilde{q}_{2}=\frac{\pi_{2}^{L}(1+\rho)}{\left(1+\pi_{2}^{L}\right)\left(\pi_{1}^{L} \pi_{2}^{L}+\rho \pi_{1}^{H} \pi_{2}^{H}\right)}
$$

where $\rho=\left(\gamma A^{H}\right) /\left((1-\gamma) A^{L}\right)$. Thus, whenever the low-risk individuals are worse off at $\left(\tilde{q}_{1}, \tilde{q}_{2}\right)$, the contracts $\left(\hat{q}_{1}^{H}, \hat{q}_{2}^{H}\right)$ and $\left(\bar{q}_{1}^{L}, \bar{q}_{2}^{L}\right)$ constitute an equilibrium. Otherwise they 
do not and the contract $\left(\tilde{q}_{1}, \tilde{q}_{2}\right)$ is the pooling equilibrium according to the definition of Wilson.

In Table 1 we provide numerical examples, for which annuity demand $A^{i}$, the contracts $\left(\hat{q}_{1}^{H}, \hat{q}_{2}^{H}\right),\left(\bar{q}_{1}^{L}, \bar{q}_{2}^{L}\right)$ and $\left(\tilde{q}_{1}, \tilde{q}_{2}\right)$, as well as expected utility $U^{i}$ of individuals of both types $i=H, L$, at these contracts are calculated explicitly. We choose three different scenarios, which differ in the share $\gamma$ of the high risk individuals (scenarios 1 and 2) and in the survival probability $\pi_{2}^{L}$ of the type- $L$ individuals in period 2 (scenarios 1 and 3). In scenario 1 the contracts $\left(\hat{q}_{1}^{H}, \hat{q}_{2}^{H}\right)$ and $\left(\bar{q}_{1}^{L}, \bar{q}_{2}^{L}\right)$ constitute an equilibrium. Taking this as a reference point, we show that a lower share $\gamma$ of type- $H$ individuals (scenario 2 ) and a higher survival probability $\pi_{2}^{L}$ of the type- $L$ individuals to period 2 (scenario 3 ) entail that there is no separating equilibrium in a competitive annuity market. In both of these scenarios $\left(\tilde{q}_{1}, \tilde{q}_{2}\right)$ constitutes the Wilson pooling equilibrium.

(b) Model with Saving in Bonds: For logarithmic utility (see (13)), we calculate demand for annuities and bonds in the first retirement period by use of the first-order conditions (5), (A17), (A18) and (A16), together with the budget constraints (A11) - (A13). For $q_{1} \geq 1 /\left(1+\pi_{2}^{i}\right)$ (that is, $K^{i}=0$; see Appendix A.2) we obtain again (A24) for annuity demand and

$$
S^{i}=\left\{\begin{array}{cl}
\frac{\pi_{1}^{i}\left(\pi_{2}^{i} q_{1}-q_{2}\right)}{1+\pi_{1}^{i}\left(1+\pi_{2}^{i}\right)} w & \text { for } q_{1}>\frac{q_{2}}{\pi_{2}^{i}} \\
0 & \text { for } q_{1} \leq \frac{q_{2}}{\pi_{2}^{i}}
\end{array}\right.
$$


for savings in bonds in the first retirement period.

The separate contract $\left(\hat{q}_{1}^{H}, \hat{q}_{2}^{H}\right)$ for type $H$ is given by (A25). The separate contract $\left(\bar{q}_{1}^{L}, \bar{q}_{2}^{L}\right)$ for type $L$ is determined by the self-selection constraint (11), and the zeroprofit-condition (6) for $i=L$. Assuming equality, one derives from (11) (making use of (A24), (A25), (A28), (13), (A17) and (A18))

(A29) $S^{H}>0$ and $\bar{q}_{1}^{L}=\frac{\pi_{1}^{H}\left(\pi_{2}^{H}\right)^{\pi_{2}^{H} /\left(1+\pi_{2}^{H}\right)}-\pi_{1}^{L} \pi_{2}^{L}}{\pi_{1}^{L}\left(1-\pi_{2}^{L}\right) \pi_{1}^{H}\left(\pi_{2}^{H}\right)^{\pi_{2}^{H}\left(1+\pi_{2}^{H}\right)}}, \bar{q}_{2}^{L}=\frac{\pi_{1}^{L}-\pi_{1}^{H}\left(\pi_{2}^{H}\right)^{\pi_{2}^{H} /\left(1+\pi_{2}^{H}\right)}}{\pi_{1}^{L}\left(1-\pi_{2}^{L}\right) \pi_{1}^{H}\left(\pi_{2}^{H}\right)^{\pi_{2}^{H} /\left(1+\pi_{2}^{H}\right)}}$ $S^{H}=0$ and (A26).

Again we determine the pooling contract $\left(\tilde{q}_{1}, \tilde{q}_{2}\right)$ which fulfills the zero-profit condition (9') and is preferred most by a type- $L$ individual. At $\left(\tilde{q}_{1}, \tilde{q}_{2}\right)$ the individual of type $L$ does not buy bonds in period 0 nor in period 1, as can be seen as follows: For any $q_{1} \geq 1 /\left(1+\pi_{2}^{L}\right)>1 /\left(1+\pi_{2}^{H}\right)$, the slope (A6) of the zero-profit condition is $-\left(\pi_{1}^{L}+\rho \pi_{1}^{H}\right) /\left(\pi_{1}^{L} \pi_{2}^{L}+\rho \pi_{1}^{H} \pi_{2}^{H}\right)<-1$, as $\partial \rho / \partial q_{t}=0$ by use of (A24). However, at points, where $S^{L}>0$, the indifference curves of a type- $L$ individual have slope -1 , and are, thus, flatter. On the other hand, at $q_{1}=1 /\left(1+\pi_{2}^{L}\right)$ with the corresponding $q_{2}$ such that the zero-profit condition (9') is fulfilled, the slope of the indifference curve is $-q_{2} /\left(\pi_{2}^{L} q_{1}\right)$. It is steeper than the slope of the zero-profit condition $-\left(\pi_{1}^{L}+\rho \pi_{1}^{H}\right) /\left(\pi_{1}^{L} \pi_{2}^{L}+\rho \pi_{1}^{H} \pi_{2}^{H}\right)$, as follows immediately, if $q_{1}=1 /\left(1+\pi_{2}^{L}\right)$ and the zeroprofit condition (9') are substituted into $-q_{2} /\left(\pi_{2}^{L} q_{1}\right)$. Hence, the (convex) indifference 
curves of a type- $L$ individual can only be tangent to the zero-profit condition, where $S^{L}=0$ and where $q_{1}>1 /\left(1+\pi_{2}^{L}\right)$, i.e. where $K^{L}=0$. As a consequence, $\left(\tilde{q}_{1}, \tilde{q}_{2}\right)$ is given by (A27).

In Table 1 numerical examples for equilibria in the model with old-age saving are given, where the same parameter constellations (Scenario $1-3$ ) are chosen as for the model without saving. Besides the respective values of the contracts $\left(\hat{q}_{1}^{H}, \hat{q}_{2}^{H}\right),\left(\bar{q}_{1}^{L}, \bar{q}_{2}^{L}\right)$ and $\left(\tilde{q}_{1}, \tilde{q}_{2}\right)$, annuity demand $A^{i}$ and indirect utility $U^{i}$, savings $S^{i}$ of both types at these contracts are included in the Table. As in the model without saving we find that in scenario 1 the contracts $\left(\hat{q}_{1}^{H}, \hat{q}_{2}^{H}\right)$ and $\left(\bar{q}_{1}^{L}, \bar{q}_{2}^{L}\right)$ constitute an equilibrium, while in scenario 2 (with a lower share $\gamma$ of type- $H$ individuals) and scenario 3 (a higher survival probability $\pi_{2}^{L}$ of the type- $L$ individuals) no separating equilibrium exists. In the latter two scenarios $\left(\tilde{q}_{1}, \tilde{q}_{2}\right)$ constitute the Wilson pooling equilibrium.

(c) Model with mandatory actuarially fair public pension system: In Table 2 we provide numerical computations to illustrate whether the existence of the equilibrium is affected by a mandatory fully-funded public pension system. To do so, we take the computations in Table 1 as a reference point. Thus, we consider the same three scenarios as in Table 1, however now we assume that each individual has to pay contributions $T$ to a public pension system, which offers constant actuarially fair pension benefits according to the average life-expectancy of the population. Thus the budget equations in the three periods read 


$$
\begin{aligned}
& c_{0}^{i}=w-A^{i}-T, \\
& c_{1}^{i}=q_{1} A^{i}+b T, \\
& c_{2}^{i}=q_{2} A^{i}+b T,
\end{aligned}
$$

where $b$ denotes the actuarially fair benefit rate offered per unit of pension contribution $T$ in each period of retirement $t=1,2$, with

$$
b=\frac{1}{(1-\gamma)\left(\pi_{1}^{L}+\pi_{1}^{L} \pi_{2}^{L}\right)+\gamma\left(\pi_{1}^{H}+\pi_{1}^{H} \pi_{2}^{H}\right)} .
$$

Annuity demand $A^{i}, i=L, H$, in the presence of a public pension system is then determined by the first-order condition (5), together with the budget constraints (A30) (A32). Assuming again logarithmic utility (13), we have as the interior solution of the maximisation problem ${ }^{14}$

$$
A^{i}>0 \text { and } \frac{1}{w-A^{i}-T}=\frac{\pi_{1}^{i} q_{1}}{q_{1} A^{i}+b T}+\frac{\pi_{1}^{i} \pi_{2}^{i} q_{1}}{q_{2} A^{i}+b T}
$$

(A34) makes obvious that annuity demand $A^{i}$ depends on the annuity payoffs $q_{1}$ and $q_{2}$, which is in contrast to the findings in the model without a public pension system. Consequently, apart from the separate contract $\left(\hat{q}_{1}^{H}, \hat{q}_{2}^{H}\right)$ for type $H$, which is again given by (A25), the separate contract $\left(\bar{q}_{1}^{L}, \bar{q}_{2}^{L}\right)$ for type $L$ as well as the pooling contract $\left(\tilde{q}_{1}, \tilde{q}_{2}\right)$ can be computed only numerically. The separate contract $\left(\bar{q}_{1}^{L}, \bar{q}_{2}^{L}\right)$ for type $L$ is 
determined by the zero-profit-condition (6) for $i=L$, by the self-selection constraint (11) and by use of (A25), (A31) - (A34) and (13) for $i=H$. As in the model without a public pension system, the pooling contract $\left(\tilde{q}_{1}, \tilde{q}_{2}\right)$ is the one which maximises utility (13) for $i=L$ and fulfils, together with (A34) for $i=L, H$, the zero-profit condition (9').

For each scenario we vary the contributions $T$ to public pensions system (5 \%, $15 \%$ and $25 \%$ of the labour income $w)$ and plot the respective values of the contracts $\left(\hat{q}_{1}^{H}, \hat{q}_{2}^{H}\right)$, $\left(\bar{q}_{1}^{L}, \bar{q}_{2}^{L}\right)$ and $\left(\tilde{q}_{1}, \tilde{q}_{2}\right)$, as well as annuity demand $A^{i}$ and indirect utility $U^{i}$ of both types $i=L, H$ at these contracts and find the following results: In scenario 1 , the introduction of the public pension system (irrespective of its size) does not change the result that the contracts $\left(\hat{q}_{1}^{H}, \hat{q}_{2}^{H}\right)$ and $\left(\bar{q}_{1}^{L}, \bar{q}_{2}^{L}\right)$ constitute an equilibrium. On the other hand, in Scenario 2 (with a lower share $\gamma$ of type- $H$ individuals than in Scenario 1 ) the introduction of a mandatory public pension system changes the results: Now, a separating equilibrium exists (again for all three values of $T$ ), while it did not in the absence of public pension system. In this case, each type of individual $i=L, H$ is better off at her separate contract $\left(\bar{q}_{1}^{L}, \bar{q}_{2}^{L}\right)$ and $\left(\hat{q}_{1}^{H}, \hat{q}_{2}^{H}\right)$, resp., than at the pooling contract $\left(\tilde{q}_{1}, \tilde{q}_{2}\right)$. The same result is found in Scenario 3 for the highest value of contributions to the public pension system $(T=250)$. However for lower values of $T=50,150$, no separating equilibrium exists, which corresponds to the result found in the model without a public pension system. In this case $\left(\tilde{q}_{1}, \tilde{q}_{2}\right)$ constitute the Wilson pooling equilibrium.

14 Note that for a sufficiently large public pension system annuity demand of an individual can be zero. 


\section{Table 1}

Numerical illustration of the (non-)existence of separating equilibria for log utility

\begin{tabular}{|c|c|c|c|c|c|c|c|}
\hline \multicolumn{8}{|c|}{$w=1000, \gamma=0.6, \pi_{1}^{H}=0.8, \pi_{2}^{H}=0.6, \pi_{1}^{L}=0.7, \pi_{2}^{L}=0.2$} \\
\hline \multicolumn{3}{|c|}{ Model without Saving in Bonds: } & \multirow{3}{*}{\multicolumn{5}{|c|}{$\begin{array}{l}\text { Model with Saving in Bonds: } \\
A^{H}=561.4, S^{H}=350.9\left(0.6 q_{1}-q_{2}\right), \\
A^{L}=456.5, S^{L}=380.4\left(0.2 q_{1}-q_{2}\right) .\end{array}$}} \\
\hline$A^{H}=561.4$, & & & & & & & \\
\hline$A^{L}=456.5$ & & & & & & & \\
\hline contracts & $U^{H}$ & $U^{L}$ & contracts & $U^{H}$ & $U^{L}$ & $S^{H}$ & $S^{L}$ \\
\hline$\hat{q}_{1}^{H}=0.781, \hat{q}_{2}^{H}=0.781$ & 13.871 & 11.235 & $\hat{q}_{1}^{H}=0.781, \hat{q}_{2}^{H}=0.781$ & 13.871 & 11.235 & 0 & 0 \\
\hline $\bar{q}_{1}^{L}=1.376, \bar{q}_{2}^{L}=0.307$ & 13.871 & 11.500 & $\bar{q}_{1}^{L}=1.407, \bar{q}_{2}^{L}=0.107$ & 13.871 & 11.412 & 258.8 & 66.5 \\
\hline$\tilde{q}_{1}=1.090, \quad \tilde{q}_{2}=0.462$ & 13.885 & 11.394 & $\tilde{q}_{1}=1.090, \quad \tilde{q}_{2}=0.462$ & 13.902 & 11.394 & 67.1 & 0 \\
\hline
\end{tabular}

Scenario 2: Non-existence of a separating equilibrium, existence of a Wilson equilibrium $\left(\tilde{q}_{1}, \tilde{q}_{2}\right)$ $w=1000, \gamma=\mathbf{0 . 2}, \pi_{1}^{H}=0.8, \pi_{2}^{H}=0.6, \pi_{1}^{L}=0.7, \pi_{2}^{L}=0.2$.

\begin{tabular}{|c|c|c|c|c|c|c|c|}
\hline \multicolumn{3}{|c|}{$\begin{array}{l}\text { Model without Saving in Bonds: } \\
A^{H}=561.4 \\
A^{L}=456.5\end{array}$} & \multicolumn{5}{|c|}{$\begin{array}{l}\text { Model with Saving in Bonds: } \\
A^{H}=561.4, S^{H}=350.9\left(0.6 q_{1}-q_{2}\right), \\
A^{L}=456.5, S^{L}=380.4\left(0.2 q_{1}-q_{2}\right) .\end{array}$} \\
\hline contracts & $U^{H}$ & $U^{L}$ & contracts & $U^{H}$ & $U^{L}$ & $S^{H}$ & $S^{L}$ \\
\hline$\hat{q}_{1}^{H}=0.781, \hat{q}_{2}^{H}=0.781$ & 13.871 & 11.235 & $\hat{q}_{1}^{H}=0.781, \hat{q}_{2}^{H}=0.781$ & 13.871 & 11.235 & 0 & 0 \\
\hline $\bar{q}_{1}^{L}=1.376, \bar{q}_{2}^{L}=0.307$ & 13.871 & 11.500 & $\bar{q}_{1}^{L}=1.407, \quad \bar{q}_{2}^{L}=0.107$ & 13.871 & 11.412 & 258.8 & 66.5 \\
\hline$\tilde{q}_{1}=1.152, \quad \tilde{q}_{2}=0.758$ & 14.166 & 11.502 & $\tilde{q}_{1}=1.152, \quad \tilde{q}_{2}=0.758$ & 14.166 & 11.502 & 0 & 0 \\
\hline
\end{tabular}

Scenario 3: Non-existence of a separating equilibrium, existence of a Wilson equilibrium $\left(\tilde{q}_{1}, \tilde{q}_{2}\right)$ $w=1000, \gamma=0.6, \pi_{1}^{H}=0.8, \pi_{2}^{H}=0.6, \pi_{1}^{L}=0.7, \pi_{2}^{L}=\mathbf{0 . 5}$.

Model without Saving in Bonds:

$A^{H}=561.4$,

$A^{L}=512.2$.

\begin{tabular}{c|c|c|c|c|c|c|c|} 
contracts & $U^{H}$ & $U^{L}$ & contracts & $U^{H}$ & $U^{L}$ & $S^{H}$ & $S^{L}$ \\
\hline$\hat{q}_{1}^{H}=0.781, \hat{q}_{2}^{H}=0.781$ & 13.871 & 12.481 & $\hat{q}_{1}^{H}=0.781, \hat{q}_{2}^{H}=0.781$ & 13.871 & 12.481 & 0 & 0 \\
$\bar{q}_{1}^{L}=1.250, \bar{q}_{2}^{L}=0.357$ & 13.871 & 12.536 & $\bar{q}_{1}^{L}=1.343, \bar{q}_{2}^{L}=0.171$ & 13.871 & 12.508 & 222.9 & 171.0 \\
\hline$\tilde{q}_{1}=0.875, \quad \tilde{q}_{2}=0.774$ & 13.956 & 12.557 & $\tilde{q}_{1}=0.875, \tilde{q}_{2}=0.774$ & 13.956 & 12.557 & 0 & 0 \\
\hline
\end{tabular}




\section{Table 2}

Numerical computations of the effects of a mandatory actuarially fair pension system on the (non-)existence of separating equilibria

\begin{tabular}{|c|c|c|c|c|c|c|c|c|c|c|c|c|c|c|}
\hline cenario 1: $w=100$ & $0, \gamma=0$ & $\overline{\pi_{1}^{H}}=$ & $8, \pi_{2}^{\prime}$ & .6 & $.7, \pi_{2}^{L}=0.2$ & $b=$ & & & & & & & & \\
\hline Existence of a separat & ng equi & ibrium & $T=50$ & & Existence of a separat & ing equ & librium & $T=150$ & & Existence of a separati & ing equ & libriun & $T=250$ & \\
\hline contracts & $A^{H}$ & $A^{L}$ & $U^{H}$ & $U^{L}$ & contracts & $A^{2}$ & $A^{2}$ & $U^{H}$ & $U^{L}$ & & $A^{2}$ & $A^{L}$ & $U^{H}$ & $U^{L}$ \\
\hline$\hat{q}_{1}^{H}=0.781, \quad \hat{q}_{2}^{H}=0.781$ & 507.9 & 402.2 & 13.887 & 11.249 & $\hat{q}_{1}^{H}=0.781, \quad \hat{q}_{2}^{H}=0.781$ & 400.9 & 293.5 & 13.924 & 11.278 & $\hat{q}_{1}^{H}=0.781, \quad \hat{q}_{2}^{H}=0.781$ & 293.9 & 184.9 & 13.960 & 11.306 \\
\hline $\bar{q}_{1}^{L}=1.373, \quad \bar{q}_{2}^{L}=0.277$ & 500.3 & 406.3 & 13.887 & 11.489 & $\bar{q}_{1}^{L}=1.388, \quad \bar{q}_{2}^{L}=0.204$ & 380.6 & 310.6 & 13.924 & 11.470 & $\bar{q}_{1}^{L}=1.407, \bar{q}_{2}^{L}=0.106$ & 266.8 & 221.2 & 13.960 & 11.445 \\
\hline$\tilde{q}_{1}=1.113, \quad \tilde{q}_{2}=0.412$ & 504.9 & 406.0 & 13.881 & 11.395 & $\tilde{q}_{1}=1.171, \quad \tilde{q}_{2}=0.287$ & 385.6 & 306.0 & 13.885 & 11.398 & $\tilde{q}_{1}=1.241, \quad \tilde{q}_{2}=0.139$ & 262.6 & 211.0 & 13.915 & 11.400 \\
\hline
\end{tabular}

\begin{tabular}{|c|c|c|c|c|c|c|c|c|c|c|c|c|c|c|}
\hline \multicolumn{5}{|c|}{$\begin{array}{l}\text { Scenario 2: } w=1000, \gamma=\mathbf{0 . 2}, \pi_{1}^{H}=0.8, \pi_{2}^{H} \\
\text { Existence of a separating equilibrium: } T=50\end{array}$} & \multicolumn{5}{|c|}{$b=1.078$} & \multicolumn{5}{|c|}{ Existence of a separating equilibrium: $T=250$} \\
\hline contracts & $A^{H}$ & $A^{L}$ & $U^{H}$ & $U^{L}$ & contracts & $A^{H}$ & $A^{L}$ & $U^{H}$ & $U^{L}$ & & $A^{H}$ & $A^{L}$ & $U^{H}$ & $U^{L}$ \\
\hline$\hat{q}_{1}^{H}=0.781, \quad \hat{q}_{2}^{H}=0.781$ & 503.1 & 396.2 & 13.913 & 11.269 & $\hat{q}_{1}^{H}=0.781, \quad \hat{q}_{2}^{H}=0.781$ & 386.5 & 275.6 & 13.997 & 11.336 & $\hat{q}_{1}^{H}=0.781, \quad \hat{q}_{2}^{H}=0.781$ & 269.8 & 155.0 & 14.077 & 11.401 \\
\hline $\bar{q}_{1}^{L}=1.374, \quad \bar{q}_{2}^{L}=0.271$ & 494.1 & 401.3 & 13.913 & 11.505 & $\bar{q}_{1}^{L}=1.392, \quad \bar{q}_{2}^{L}=0.183$ & 363.2 & 297.6 & 13.997 & 11.516 & $\bar{q}_{1}^{L}=1.416, \quad \bar{q}_{2}^{L}=0.065$ & 240.9 & 200.9 & 14.077 & 11.520 \\
\hline$\tilde{q}_{1}=1.163, \quad \tilde{q}_{2}=0.717$ & 508.4 & 406.0 & 14.163 & 11.503 & $\tilde{q}_{1}=1.196, \quad \tilde{q}_{2}=0.597$ & 398.6 & 304.8 & 14.155 & 11.505 & $\tilde{q}_{1}=1.255, \quad \tilde{q}_{2}=0.396$ & 278.7 & 203.8 & 14.149 & 11.508 \\
\hline
\end{tabular}

\begin{tabular}{|c|c|c|c|c|c|c|c|c|c|c|c|c|c|c|}
\hline \multicolumn{15}{|c|}{ Scenario 3: $w=1000, \gamma=0.6, \pi_{1}^{H}=0.8, \pi_{2}^{H}=0.6, \pi_{1}^{L}=0.7, \pi_{2}^{L}=\mathbf{0 . 5}$} \\
\hline contracts & $A^{H}$ & $A^{L}$ & $U^{H}$ & $U^{L}$ & contracts & $A^{H}$ & $A^{L}$ & $U^{H}$ & $U^{L}$ & & $A^{H}$ & $A^{L}$ & $U^{H}$ & $U^{L}$ \\
\hline$\hat{q}_{1}^{H}=0.781, \quad \hat{q}_{2}^{H}=0.781$ & 509.7 & 460.3 & 3.879 & 2.489 & $\hat{q}_{1}^{H}=0.781, \quad \hat{q}_{2}^{H}=0.781$ & 406.3 & 356.5 & 13.897 & 12.505 & 31, $\hat{q}_{2}^{H}=$ & 302.9 & 252.8 & 3.914 & 12.521 \\
\hline $\bar{q}_{1}^{L}=1.264, \quad \bar{q}_{2}^{L}=0.330$ & 504.7 & 456.7 & 13.879 & 12.542 & $\bar{q}_{1}^{L}=1.298, \quad \bar{q}_{2}^{L}=0.260$ & 391.9 & 348.1 & 13.897 & 53 & $\bar{q}_{1}^{L}=1.349, \quad \bar{q}_{2}^{L}=0.160$ & 280.8 & 243.7 & & 12.562 \\
\hline$\tilde{q}_{1}=0.879, \quad \tilde{q}_{2}=0.764$ & 511.2 & 462.1 & 13.956 & 11.557 & $\tilde{q}_{1}=0.894, \quad \tilde{q}_{2}=0.735$ & 410.4 & 361.7 & 13.955 & 12.557 & $\tilde{q}_{1}=0.928, \quad \tilde{q}_{2}=0.672$ & 308.7 & 261.0 & 13.953 & 12.557 \\
\hline
\end{tabular}




\section{References}

ABEL, A. B. [1986], "Capital Accumulation and Uncertain Lifetimes with Adverse Selection," Econometrica, 54, 1079-1097.

Brown, J. R. [2001], "Private pensions, mortality risk, and the decision to annuitize," Journal of Public Economics, 82, 29-62.

Brown, J. R., O. S. Mitchell, And J. M. Poterba [2001], "The Role of Real Annuities and Indexed Bonds in an Individual Accounts Retirement Program," pp. 321360 in: J. Y. Campbell and M. Feldstein (eds.), Risk Aspects of InvestmentBased Social Security Reform, University of Chicago Press: Chicago.

BRUnNeR, J. K. AND S. PECH [2002], "Adverse selection in the annuity market with sequential and simultaneously insurance demand," Working paper, 0204, Department of Economics, University of Linz, Austria.

Eckstein, Z, M. Eichenbaum, And D. Peled [1985], "Uncertain Lifetimes and the Welfare Enhancing Properties of Annuity Markets and Social Security," Journal of Public Economics, 26, 303-326.

FELDSTEIN, M. [1990], "Imperfect annuity markets, unintended bequests, and the optimal age structure of social security benefits," Journal of Public Economics, 41, 31-43.

Finkelstein, A. And J. M. Poterba [2002], "Selection Effects in the United Kingdom Individual Annuities Market," Economic Journal, 112 (476), 28-50.

FinKelstein, A. AND J. M. POTERBA [2004], "Adverse Selection in Insurance Markets: Policyholder Evidence from the U.K. Annuity Market," Journal of Political Economy, 112, 183-208.

Friedman, B. M. AND M. J. WARSHAWSKY [1988], "Annuity Prices and Saving Behaviour in the United States," pp. 53-77 in: Z. Bodie, J. Shoven and D. Wise (eds.), Pensions in the U.S. Economy, University of Chicago Press: Chicago.

FriedMAN, B. M. AND M. J. WARSHAWSKY [1990], "The Cost of Annuities: Implications for Saving Behaviour and Bequests," Quarterly Journal of Economics, 105, 135-154. 
HeLLWIG M. [1987], "Some recent developments in the theory of competition in markets with adverse selection," European Economic Review, 31, 319-325.

Mas-Colell, A., M. D. Whinston, And J. R. Green [1995], Microeconomic Theory, Oxford University Press: Oxford.

Mitchell, O. S., J. M. Poterba, M. J. Warshawsky, And J. R. Brown [1999], "New Evidence on the Money's Worth of Individual Annuities," American Economic Review, 89, 1299-1318.

Moore, J. F. AND O. S. Mitchell [2000], "Projected Retirement Wealth and Savings Adequacy in the Health and Retirement Study," pp. 68-94 in: O. S. Mitchell, B. Hammond, and A. Rappaport (eds.), Forecasting Retirement Needs and Retirement Wealth, Pension Research Council, University of Pennsylvania Press: Philadelphia.

Pauly, M. V. [1974], "Overinsurance and Public Provision of Insurance: The Roles of Moral Hazard and Adverse Selection," Quarterly Journal of Economics, 88, 44-62.

RILEY, J. G. [1979], "Informational equilibrium," Econometrica, 47, 331-359.

RothsCHILD, M. AND J. STIGLITZ [1976], "Equilibrium in Competitive Insurance Markets: An Essay on the Economics of Imperfect Information," Quarterly Journal of Economics, 90, 629-649.

TOWNLEY, P. G. C. AND R. W. BoADWAY [1988], "Social Security and the Failure of Annuity Markets," Journal of Public Economics, 35, 75-96.

WALLISER, J. [2000], "Adverse Selection in the Annuities Market and the Impact of Privatizing Social Security," Scandinavian Journal of Economics, 102, 373393.

WiLson, CH. [1977], "A Model of Insurance Markets with Incomplete Information," Journal of Economic Theory, 16, 167-207.

YAARI, M. E. [1965], "Uncertain Lifetime, Life Insurance, and the Theory of the Consumer," Review of Economic Studies, 32, 137-150. 